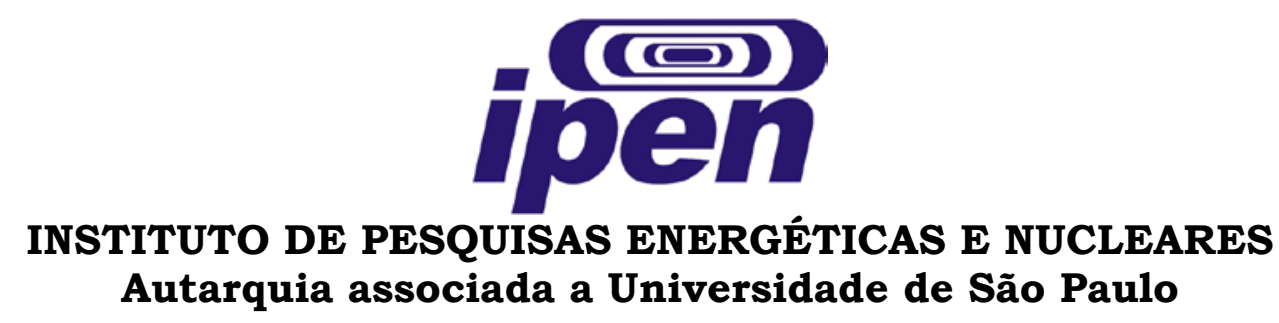

Análise mecânica de réguas ósseas esterilizadas por radiação gama para uso em Bancos de Tecidos

Luis Otavio Carvalho Kosmiskas

Dissertação apresentada como parte dos requisitos para obtenção do grau de Mestre em Ciências na Área de Tecnologia Nuclear - Aplicações.

Orientadora:

Mônica Beatriz Mathor

São Paulo, 2007 
INSTITUTO DE PESQUISAS ENERGÉTICAS E NUCLEARES Autarquia associada a Universidade de São Paulo

Análise mecânica de réguas ósseas esterilizadas por radiação gama para uso em Bancos de Tecidos

Luis Otavio Carvalho Kosmiskas

Dissertação apresentada como parte dos requisitos para obtenção do grau de Mestre em Ciências na Área de Tecnologia Nuclear - Aplicações.

Orientadora:

Mônica Beatriz Mathor 


\section{Agradecimentos}

Agradeço a todos aqueles que, direta ou indiretamente, auxiliaram na realização deste trabalho:

À Dra. Mônica Beatriz Mathor, sem a qual este trabalho nunca poderia ter sido realizado;

Ao Dr. Luis Filipe P. C. de Lima, pelo auxílio prestado no uso do Dynamical Mechanical Analizer;

Ao Dr. Luiz Vicente Gomes Tarelho, por ceder o uso da Isomet durante os estágios iniciais de desenvolvimento deste projeto;

À Cynara Viterbo Montoya, pelos conselhos e auxílio na área de estatística e pelo grande suporte;

Ao José Jorge Ambiel, pelo auxílio no desenvolvimento dos dispositivos de suporte das amostras;

Ao setor DPF do IPEN, especialmente a José Carlos Sabino, Jose Maria Jardim, Joaquim Moreira dos Santos, Gilson Carlos Victorino e Marcos do Santos, pela contribuição profissional na execução dos suportes; biomecânicos;

Ao Dr. Eddy S. Pino, pelos conselhos e auxílio na área de ensaios

Ao Dr. José Eduardo Manzoli, pelo auxílio na área de mecânica e pelo grande interesse demonstrado neste trabalho; biomecânicos;

Ao Djalma Batista Dias pelo auxílio técnico nos ensaios

Ao Centro de Tecnologia das Radiações -CTR - Ipen/CNEN-SP, na pessoa do Dr. Wilson P. Calvo e aos colegas do centro, pela utilização dos equipamentos, disponibilidade e auxilio durante a realização deste trabalho;

Ao CNPq pela bolsa de Mestrado. 


\title{
Análise mecânica de réguas ósseas esterilizadas por radiação gama para uso em Bancos de Tecidos
}

\section{Luis Otavio Carvalho Kosmiskas}

\begin{abstract}
RESUMO
Ao se trabalhar com materiais para a área de saúde, uma das principais considerações é evitar possiveis contaminações, dada a natureza da sua aplicação. Dentre os métodos desenvolvidos para esterilização, a radiação ionizante tem sido amplamente empregada por inúmeros setores da área de saúde pela sua eficácia em eliminar contaminantes biológicos de diversas origens. A problemática da utilização da radiação ionizante em materiais de origem humana, contudo, vai além da questão de sua eficácia como esterilizante, incluindo as possíveis alterações na estrutura do material de escolha. Desta forma, no presente trabalho, buscou-se avaliar qual a extensão das alterações biomecânicas causadas pela radiação em tecidos ósseos. Mais especificamente avaliamos as alterações no módulo de elasticidade, tensão de ruptura e porcentagem de deformação que decorrem do processo de irradiação. Como modelo de eleição foram escolhidas réguas ósseas retiradas da diáfase de fêmures bovinos, simulando as condições de ossos humanos armazenados em Bancos de Tecidos Biológicos. Estas foram congeladas a $-70^{\circ} \mathrm{C}$ e expostas a doses crescentes de radiação gama $(0,12.5,25$ e 50 kGy). Durante o trabalho foi desenvolvido um sistema de cortes para obtenção de amostras precisas e homogêneas. Os resultados demonstram que há uma diferença significativa entre as características observadas com o aumento da dose de radiação.
\end{abstract}




\title{
Mechanical analysis of bone rulers sterilized by gama radiation for use in Tissue Banks
}

\section{Luis Otavio Carvalho Kosmiskas}

\begin{abstract}
In the production process of health care products, contamination must be considered as one of the principal hazards to be avoided. Among the developed methods for sterilization, ionizing radiation has largely been used by many sectors in health care area as it is efficient in eliminating biological contaminants of several origins. The difficulty of deploying ionizing radiation in materials of human origin, though, includes which possible alterations it might cause in human tissue. In the present work, the extension of the biomechanical alteration generated by radiation in bone tissue was evaluated by biomechanical methods. More specifically, we evaluated alterations to the elastic modulus, rupture tension and percentage of deformation that are thought to be a consequence of the sterilization process. As a research model, bovine femur struts obtained from the diaphysis were used. The struts were frozen in a temperature of $-70{ }^{\circ} \mathrm{C}$ and irradiated with crescent doses of gamma radiation $(0,12.5,25$ e $50 \mathrm{kGy})$. During this work, a cutting system to obtain precision samples to use in such essays was developed. As results show that there is a significant different between the analyzed characteristics in the different doses of radiation.
\end{abstract}




\section{SUMÁRIO}

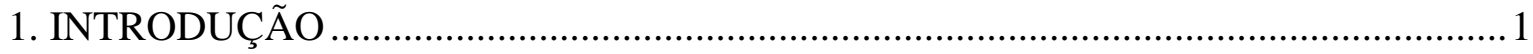



3. REVISÃO DA LITERATURA …...............................................................

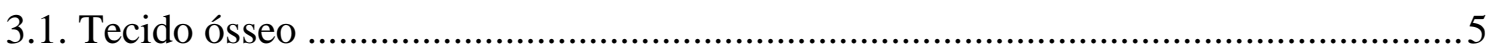

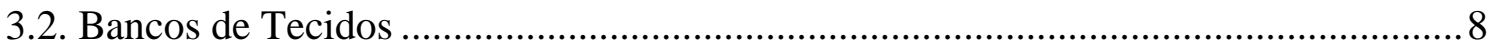

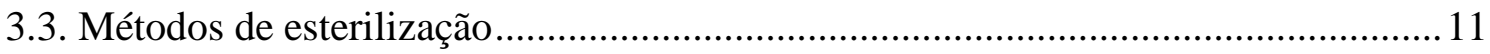

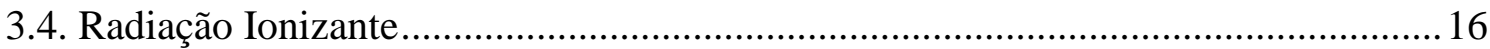



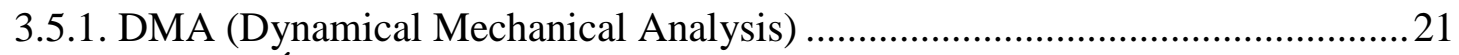





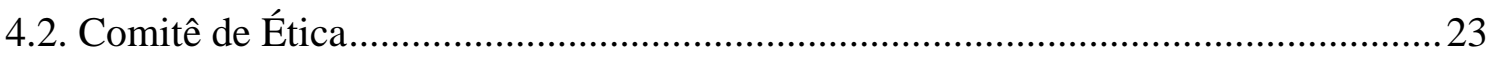



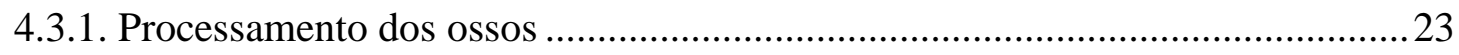

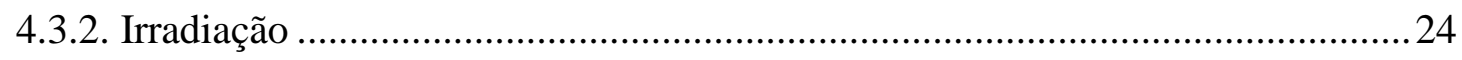



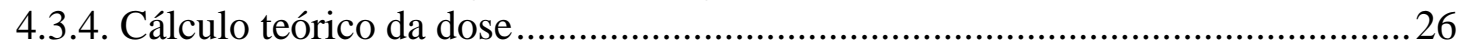

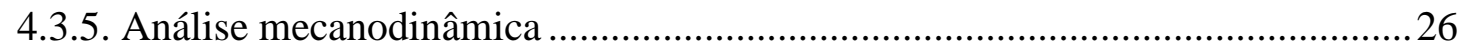

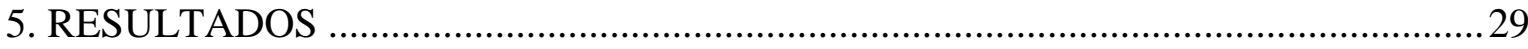

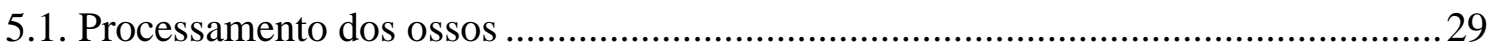

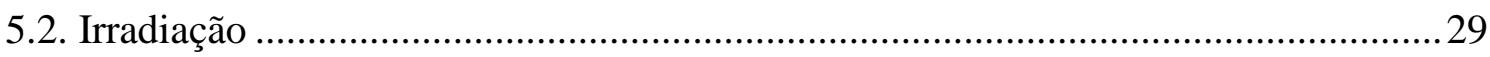

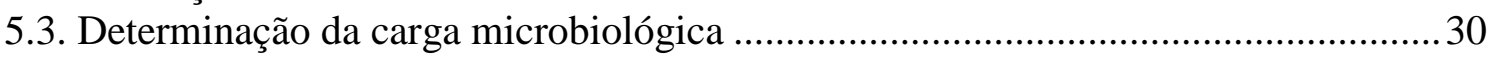

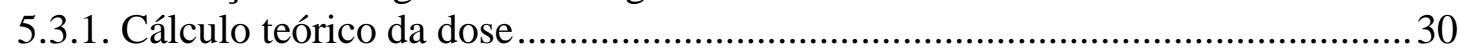



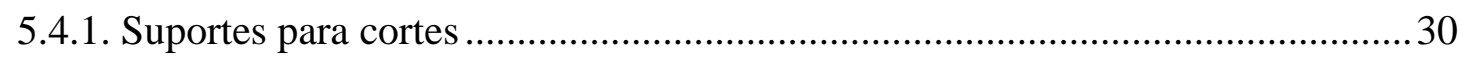

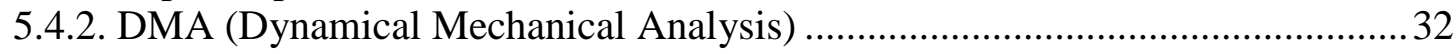

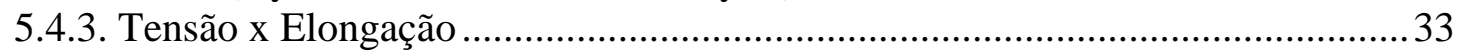

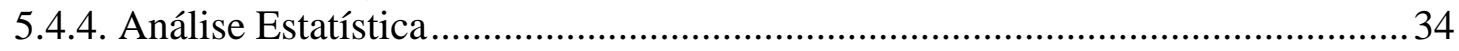

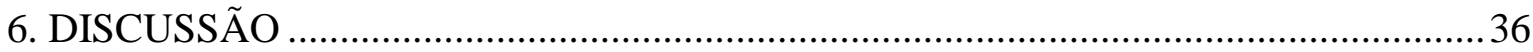

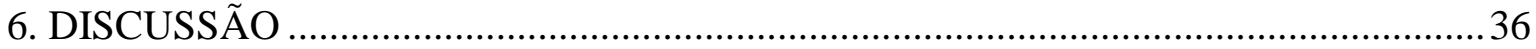

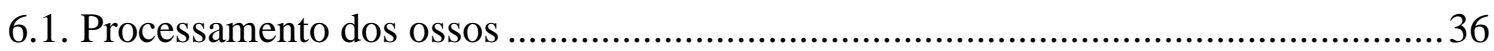

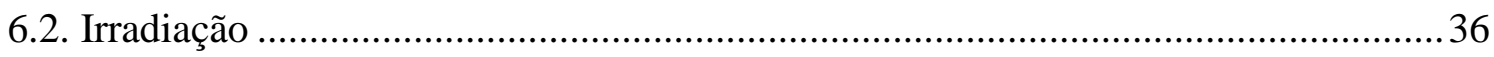

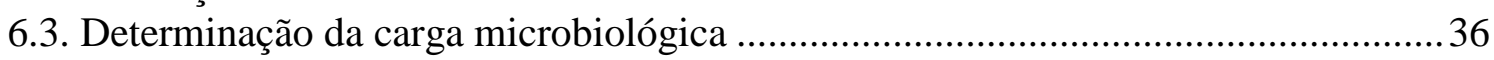

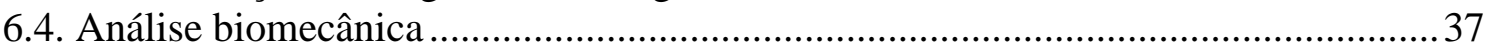

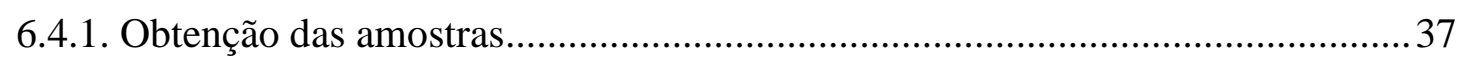

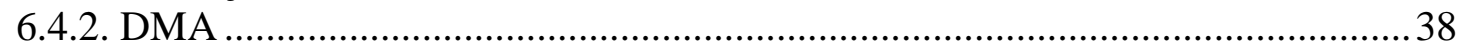

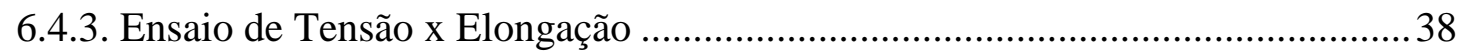

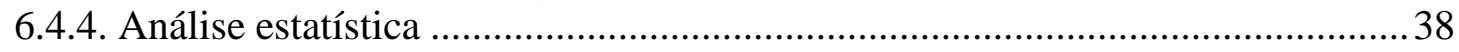

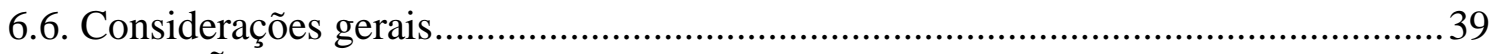

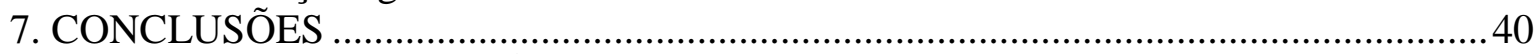






\section{INTRODUÇÃO}

Ao se trabalhar com materiais para a área de saúde, uma das principais considerações é evitar possíveis contaminações (RUTALA \& WEBER, 2004) dada a natureza da sua aplicação. Com o objetivo de se evitar tais ocorrências, inúmeras técnicas que visam diminuir ou eliminar as mesmas foram desenvolvidas, com a eficácia dos resultados obtidos variando muito dependendo do material a ser tratado e o objetivo da aplicação (BLOCK, 1991).

Dentre os métodos desenvolvidos para esterilização, a radiação ionizante tem sido amplamente empregada por inúmeros setores da área de saúde (SILVERMAN, 1991) dada sua eficácia em eliminar contaminantes biológicos de diversas origens. A preferência pela utilização desta técnica, está relacionada a alguns fatores, tais como, a facilidade do procedimento, desde que se tenha acesso às instalações necessárias, pelo fato desse não implicar em alterações significativas do material, além de ser efetuada após a embalagem final (DZIEDZIC-GOCLAWSKA et al, 2005).

Em se tratando de materiais de origem humana, tais como sangue e tecidos, a problemática da contaminação atinge em novo patamar: como a maioria destes produtos tem acesso direto a corrente sangüinea e/ou órgãos vitais, a tolerância frente à contaminação deve ser inexistente (RUTALA \& WEBER, 2004). As conseqüências da esterilização ineficaz são inúmeras e podem variar desde a inutilização e perda do material até o desenvolvimento de um grave quadro infeccioso no paciente.

Levando em conta tais considerações, houve uma tendência ao uso das radiações ionizantes para esterilização de materiais de origem humana. Tais procedimentos já vêm sendo empregados (DZIEDZICGOCLAWSKA et al, 2005), porém existe uma relação complexa entre a dose de radiação utilizada com o objetivo de esterilizar o tecido, a natureza da carga microbiológica presente, as alterações que podem ser causadas no material pela exposição à radiação e as implicações finais quanto ao uso. 
Vários estudos vêm sendo feitos com o objetivo de avaliar os prováveis efeitos da radiação ionizante em tecidos biológicos (BOURROUL, 2004; DZIEDZIC-GOCLAWSKA, 2005). O grupo de Tecidos Biológicos do Instituto de Pesquisas Energéticas e Nucleares (IPEN), em conjunto com o Banco de Tecidos do Instituto Central do Hospital das Clínicas da Faculdade de Medicina da USP (HC-FMUSP), vem desenvolvendo, desde o ano de 2000, estudos relacionados com estes efeitos, mais especificamente com enxertos de pele (BOURROUL, 2004). Dando continuidade a estes estudos, o grupo vem avaliando os prováveis efeitos da radiação ionizante em outros tecidos biológicos.

Além disso, a Agência Internacional de Energia Atômica (IAEA, do inglês International Atomic Energy Agency) tem promovido e prestado suporte ao uso da radiação ionizante para esterilização, tendo fornecido suporte técnico, científico e financeiro a tais projetos (DZIEDZICGOCLAWSKA, 2000).

Desta forma, no presente trabalho, buscaremos avaliar qual a extensão das alterações causadas pela radiação em tecidos ósseos. Mais especificamente estaremos avaliando as alterações mecânicas que decorrem deste processo de irradiação. Como modelo de eleição foram escolhidas réguas ósseas retiradas da diáfase de fêmures. Tais réguas são empregadas na prática cirúrgica ortopédica como substitutos para algumas próteses em cirurgias reconstrutivas (HADDAD \& DUNCAN, 2003).

Contudo, a utilização de ossos humanos para pesquisa é restrita devido à prioridade destes para utilização em transplantes. Tendo em vista a necessidade de um desenvolvimento inicial da metodologia para avaliar a adequação dos ossos após o tratamento com radiação e que tal desenvolvimento estaria consumindo ossos necessários para transplante, optou-se pela utilização de ossos bovinos durante este trabalho. Tal desenvolvimento está de acordo com o estabelecido na Portaria $n^{\circ} 263$ de 31 de março de 1999, que em seu artigo $1^{\circ}$ estabelece que "A utilização de tecidos, órgãos ou partes do corpo humano para fins científicos somente 
será permitida depois de esgotadas as possibilidades de sua utilização em transplantes".

Análises posteriores com ossos humanos serão necessárias para a validação dos resultados obtidos com ossos bovinos. Contudo estima-se uma redução significativa na quantidade de material utilizada graças à padronização atingida no atual estudo. 


\section{OBJETIVOS}

Os objetivos deste trabalho foram:

- Desenvolver um sistema de cortes precisos para preparação de amostras originárias de ossos.

- Avaliação do módulo de elasticidade dos ossos bovinos congelados, comparando-se irradiados e não irradiados. 


\section{REVISÃO DA LITERATURA}

\subsection{Tecido ósseo}

O tecido ósseo é uma especialização do tecido conjuntivo, tendo como principal característica a mineralização da matriz extracelular, importante para as funções de proteção, de órgãos internos e sustentação, relacionadas com este tecido. A mineralização também tem papel importante na homeostase já que os ossos são fonte de armazenamento de minerais (DOWNEY \& SIEGEL, 2006). As populações celulares que compõe este tecido são:

- Osteoblastos: São a base originária da maioria das células que compões o tecido ósseo, sendo responsáveis pela produção da matriz óssea não mineralizada (osteóide). Tem origem em células mesenquimais não diferenciadas presentes na medula, endósteo, periósteo e nos canais ósseos (DOWNEY \& SIEGEL, 2006).

- Células de revestimento ou de superficie: Uma das possiveis evoluções do osteoblasto, muitas vezes referido como osteócitos de superficie ou osteoblastos em repouso dado seu estado relativamente inativo metabolicamente. A função exata destas células ainda não foi esclarecida, porém existem inúmeras conjecturas (DOWNEY \& SIEGEL, 2006). Alguns autores sugerem que estas células sejam responsáveis pela regulação do crescimento dos cristais de hidroxiapatita ou atuem como barreira entre a matriz óssea e o líquido extracelular (MARKS \& POPPOF, 1988). Já BUCKWALTER et al, 1996 apud DOWNEY \& SIEGEL, 2006 sugere que estas células atuem na remoção do osteóide para ação dos osteoclastos.

- Osteócitos: Estima-se que mais de 90\% das células ósseas sejam osteócitos. Estes por sua vez são originados de osteoblastos que foram envolvidos pela matriz óssea. Por causa da natureza da matriz óssea, os osteócitos se encontram em lacunas desmineralizadas conectadas por canalículos, os quais contém prolongamentos citoplasmáticos dos osteócitos. Tais prolongamentos permitem que estas células se comuniquem, formando uma rede. Isso se torna importante dado que não há difusão de nutrientes pela matriz e a rede exerce um 
papel decisivo no processo de alimentação celular. Além disso, existem indícios de que a rede celular responda a estímulos mecânicos e assim coordene o processo de remodelamento (KLEIN-NULEND et al, 2005).

- Osteoclastos: Células gigantes multinucleadas originárias de precursores da linhagem de macrófagos, responsáveis pela reabsorção da matriz óssea. A reabsorção tem papel importante na homeostase, pois permite a disponibilização de minerais para o organismo. Os mecanismos efetores da reabsorção estão relacionados com a adesão do osteoclasto a regiões exposta da matriz óssea. Nestas regiões, o osteoclasto é capaz de gerar uma zona isolada de baixo $\mathrm{pH}$ onde são liberadas enzimas proteoliticas. A ação conjunta do $\mathrm{pH}$ ácido e destas enzimas leva a dissolução e posterior reabsorção da matriz óssea (ROSS \& CHRISTIANO, 2006).

Estas células, por sua vez, podem se organizar em duas estruturas ósseas distintas, o osso compacto (cortical) e o osso esponjoso (trabecular), como pode ser observado na Figura 01. O osso compacto é de maior presença no corpo humano, aparecendo em $80 \%$ do esqueleto maduro (DOWNEY \& SIEGEL, 2006). O osso esponjoso pode ser encontrado nas extremidades dos ossos longos envoltos por uma fina camada de osso compacto.



Figura 01: Macromorfologia do tecido ósseo, observada na extremidade proximal do fêmur (BONE CURRICULUM, 2005) 
As estruturas ósseas podem ainda ser compostas por osso primário (trançado) ou osso secundário (lamelar). O osso primário aparece durante o estágio embrionário e é totalmente reposto pelo osso secundário em torno dos 4-5 anos, em humanos. Em indivíduos adultos, porém, pode-se encontrar osso primário no início da recuperação de fraturas (CROCI et al, 2003), dentro das suturas cranianas e placas epifisárias (DOWNEY \& SIEGEL, 2006). A organização final dos ossos compacto e esponjoso pode ser observada na figura 02 .

\section{Osso compacto e osso esponjoso}

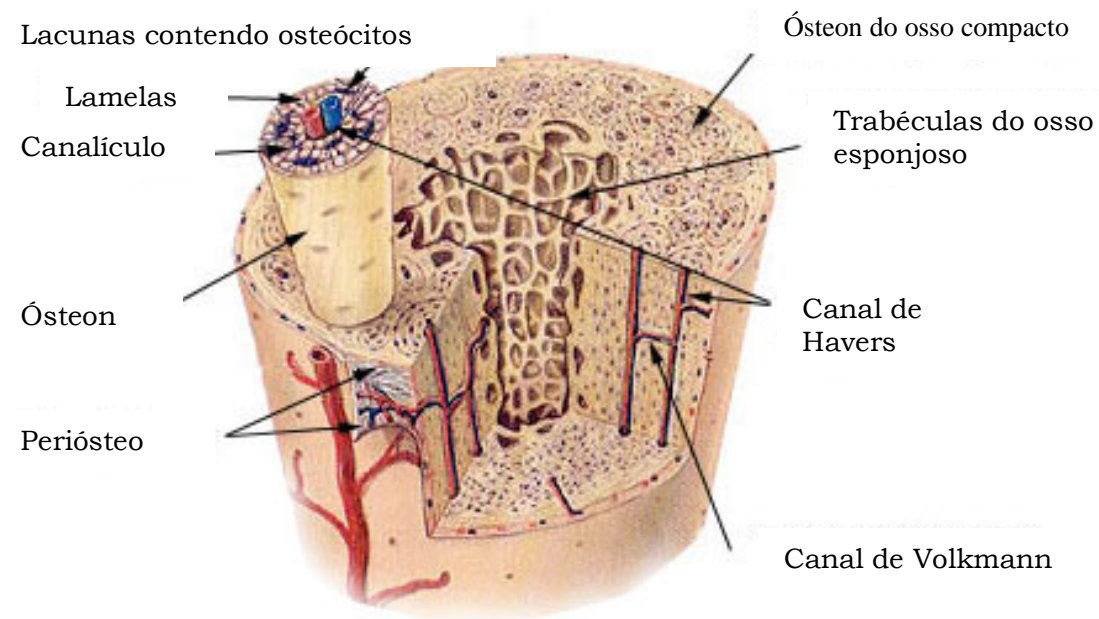

Figura 02: Organização do tecido ósseo (WIKIPEDIA, 2006).

Apesar de sua aparência rígida, o tecido ósseo está em constante mudança ou remodelação. Tal remodelação visa reconstruir o tecido para que esse se adeqüe as necessidades de tração, resistência e nutrição impostas ao organismo (DOWNEY \& SIEGEL, 2006). A efetivação do processo de remodelação se dá pela ação conjunta das células ósseas, sendo o início do processo dado pela exposição da matriz óssea decorrente da retração das células de revestimento. Paralelamente, ocorre migração dos osteoclastos para a região de matriz exposta e o começo da reabsorção da matriz, com formação de uma lacuna (Lacuna de Howship). Numa última etapa, os osteoblastos ocupam a região de reabsorção e iniciam a produção de osteóide, a qual será mineralizada após 10 dias (GOUVEIA, 
2004). A regulação deste processo é basicamente hormonal, porém ainda existem dúvidas quanto aos exatos mecanismos (KLEIN-NULEND et al, 2005).

A constante adaptação é importante para a recuperação de fraturas ou de procedimentos cirúrgicos (CROCI et al, 2003). No caso específico dos transplantes ósseos, a remodelação se apresenta como o mecanismo responsável pela incorporação do enxerto pelo paciente, permitindo assim a substituição do material enxertado por osso do próprio paciente (NATHER, 2001).

Existem duas fontes possíveis para os enxertos, o próprio paciente (enxerto autógeno) ou doadores (enxerto alógeno). O "padrão ouro" para transplante é, sem dúvida alguma, o enxerto autógeno, já que este permite a utilização de material do próprio paciente e, no caso de ossos, permite o uso de enxertos vascularizados. Estas duas condições levam a uma recuperação mais rápida (KNESER et al, 2006). Contudo o uso de enxertos autógenos sacrifica tecidos de outras partes do corpo do paciente e são problemáticos em casos em que reconstrução é massiva ou repetida (HADDAD, 2000). Uma outra possibilidade para transplantes está na utilização de enxertos originários de doadores vivos ou mortos (alógenos). Tais enxertos são mais práticos para a utilização tendo em vista que, como são obtidos de doadores, podem vir na quantidade e no formato requeridos pelo médico e não provocam maiores injúrias ao paciente. A integração do tecido nesses casos é um pouco mais lenta devido à falta de vascularização inicial (HADDAD, 2000).

\subsection{Bancos de Tecidos}

O aparecimento formal dos bancos de tecidos ocorreu à aproximadamente 60 anos nos Estados Unidos e em alguns países da Europa (MONIG \& VON VERSEN, 2000). O surgimento dos bancos acompanha o crescimento na demanda de tecidos humanos para uso em procedimentos cirúrgicos e foi responsável pelo aumento do uso rotineiro de enxertos alógenos (GALEA \& KERNEY, 2005). 
Inicialmente o uso de tecidos era desorganizado, sem critérios globais ou regulatórios, sendo norteado pelas necessidades pontuais dos médicos ou de pesquisadores. O aumento na demanda e a conscientização no uso de material de origem humana, contudo, levaram a necessidade de criação de normas e procedimentos para seleção de doadores, ablação, estocagem e uso destes tecidos (MONIG \& VON VERSEN, 2000; HERSON \& MATHOR, 2006).

Atualmente existem diversos órgãos locais e internacional que regulam o funcionamento dos bancos, como por exemplo, American Association of Tissue Banks - AATB, nos Estados Unidos e European Association of Tissue Banks - EATB, na Europa No Brasil a Agência Nacional de Vigilância Sanitária (ANVISA) fiscaliza e controla o funcionamento dos bancos assim como o uso de tecidos em transplantes, como determinado pelas seguintes legislações (HERSON et al, 2002):

- Lei n 9.434 de 04 de fevereiro de 1997 que "Dispõe sobre a remoção de órgãos, tecidos e partes do corpo humano para fins de transplante e tratamento e dá outras providências".

- Decreto $n^{\circ} 2.268$ de 30 de junho de 1997, que "Regulamenta a Lei $n^{\circ}$ 9.434, de 04 de fevereiro de 1997, que dispõe sobre a remoção de órgãos, tecidos e partes do corpo humano para fins de transplante e tratamento, e dá outras providências".

- Portaria no 3407 de 05 de agosto de 1998, que "Aprova o Regulamento Técnico sobre as atividades de transplantes e dispõe sobre a Coordenação Nacional de Transplantes".

- Lei $\mathrm{n}^{\circ} 10.211$ de 23 de março de 2001 que "Altera dispositivos da Lei $n^{\circ} 9.434$, de 4 de fevereiro de 1997, que "dispõe sobre a remoção de órgãos, tecidos e partes do corpo humano para fins de transplante e tratamento".

- Portaria n 1686 de 20 de setembro de 2002, que "Aprova, na forma do Anexo I desta Portaria, as Normas para Autorização de Funcionamento e Cadastramento de Bancos de Tecidos Musculoesqueléticos pelo Sistema Único de Saúde”. 
Além da regulação legal, muitos bancos de tecidos optam pela adesão a um sistema de gestão da qualidade tendo em vista os benefícios não só quanto ao controle de processos, mas também às conseqüentes diminuições nos custos, a oportunidade de melhorias técnicas e uma melhor adequação as necessidades dos médicos (MONIG \& VON VERSEN, 2000; HERSON \& MATHOR, 2006).

As obrigações dos Bancos de Tecidos envolvem garantir e manter as condições de uso dos tecidos para transplantes (HERSON et al, 2001). Para tanto, existe um processo inicial de seleção de doadores baseado em estudo do histórico médico e social do doador, análise de exames sorológicos e de dados do prontuário de internação, além de exame físico. Durante esta fase procura-se excluir aqueles que apresentavam:

- doenças transmissiveis graves, tais como AIDS, Hepatite B ou C, Doença de Chagas, Sífilis como alguns exemplos;

- comportamento de risco, exemplificado pelo uso de drogas injetáveis ou comportamento promíscuo;

- faixa etária inadequada para obtenção de tecidos adequados para suo (menor de 15 e maior de 60 anos);

- qualquer característica não determinada que possa representar risco, como cicatrizes de origem desconhecida, lesões cutâneas suspeitas e hepatomegalia, por exemplo (HERSON et al, 2002).

Caso seja aceita a doação, a retirada dos tecidos é feita por uma equipe médica treinada, em ambiente estéril e com a retirada estratégica ou recolocação de prótese no local, visando assim não só evitar a contaminação e a obtenção de enxertos adequados como também preservar a integridade da aparência do doador, como estabelecido pelo Decreto $\mathrm{n}^{\circ} 2.268 / 97$.

A última etapa antes do armazenamento final do tecido envolve o processamento deste. As exigências de processamento variam de acordo com o tecido obtido (HERSON et al, 2002 e VASTEL et al, 2004), porém sempre deveriam envolver a aplicação de um método de esterilização. Esta esterilização visa garantir a segurança do uso do enxerto. 
O primeiro parâmetro a ser considerado durante a esterilização é a carga microbiológica inicial presente. A determinação desta carga nos tecidos é um passo importante, pois, com base nesses dados, pode-se delimitar os parâmetros dos passos seguintes de esterilização, tendo em vista que cargas menores não necessitam de processamento mais extremo para atingir os limites aceitáveis (Security Assurance Level-SAL), para uso de aloenxertos, de 10-6 UFCs (unidades formadoras de colônia.). O SAL é um valor derivado das curvas de morte dos microrganismos e representa a chance de se encontra um microrganismo viável, no caso esta chance é de uma e um milhão (YUSOF, 2001a).

\subsection{Métodos de esterilização}

Os métodos de esterilização podem ter natureza variável, sendo físicos, químicos ou, eventualmente, uma combinação de ambos. Cada método possui características próprias as quais definem o espectro de ação e aplicação (RUSSEL, 1991). Isto implica em que, dependendo dos microorganismos a serem eliminados e/ou da aplicação do produto a ser esterilizado, os diversos métodos darão resultados variados e assim devese ter em mente qual o objetivo final do processo para escolher o método mais adequado (RUTALA \& WEBER, 2004). Outro ponto importante a considerar é se o produto a ser esterilizado não será afetado adversamente, seja direta ou indiretamente, durante o processo. Este tipo de consideração evita desperdício de material, perda de rendimento em procedimentos e mais importante para produtos da área de saúde, várias complicações para o paciente.

Alguns exemplos de métodos de esterilização atualmente empregados são:

- Calor: O emprego do calor como método de esterilização já foi consagrado. Dentre as formas possíveis estão o calor úmido, associado com vapor de água ou apenas água em ebulição, e o calor seco, onde há transferência térmica direta para o material. Ambas as formas vêem largo emprego na área da saúde. O calor úmido atua nas interfaces onde ocorre contato do material com o vapor/líquido e assim sua eficácia esta 
diretamente relacionada com o acesso ao material. Uma vez que se tenha acesso, a esterilização ocorre de maneira rápida, eficaz e relativamente barata. Já a eficácia do calor seco depende apenas da garantia que o material a ser esterilizado tenha atingido a temperatura correta, já que a transferência de energia é direta. Isto torna o método lento e demorado de maneira geral, além do fato de serem necessárias temperaturas mais elevadas do que as do calor úmido. A principal desvantagem em ambos os casos se dá pelo próprio mecanismo de ação: o calor pode danificar ou alterar as propriedades de alguns produtos, como por exemplo, alguns suplementos alimentares (JOSLYN, 1991). No caso de tecidos biológicos, o uso do calor não é recomendado, tendo em vista que as temperaturas envolvidas são suficientes para causar alterações nestes (PHILIPS, 1997)

- Filtração: Sem dúvida um dos métodos mais antigos de esterilização, a filtração é empregada, como método de separação, desde a antiguidade, porém os primeiros filtros desenhados para remoção de bactérias datam de 1884 e eram fabricados em vidro. Com o desenvolvimento dos conhecimentos técnicos sobre fabricação e sobre os microorganismos, houve também um desenvolvimento na qualidade e eficácia dos filtros. Atualmente se utilizam membranas de celulose de porosidade conhecida, que usualmente variam de 0,45 a 0,22 $\mu \mathrm{m}$. A dimensão dos poros é importante na filtração, pois a separação dos microorganismos se dá por uma barreira física que retém partículas maiores que o tamanho do poro (LEVY \& LEAHY, 1991). As dimensões dos poros acima são suficientes para reter bactérias, fungos e leveduras e tem aplicação corrente nas indústrias. Contudo a eliminação de vírus requer filtros de 15-40 $\mathrm{nm}$ e é extremamente importante para produtos derivados de plasma humano (KLEIN, 2005). A filtração é normalmente uma técnica barata e simples, porém a aplicação está limitada àqueles produtos passiveis de serem filtrados tais como soluções, líquidos ou gases (LEVY \& LEAHY, 1991).

- Óxido de etileno (ETO): Agente químico descoberto em 1859, muito eficiente na esterilização de produtos e tem sido empregado, na forma de vapor, na área médica devido a seu alto poder de penetração, 
não ser corrosivo para maioria dos materiais e de ser aplicado a baixas temperaturas. O mecanismo de ação do ETO se dá pela alquilação de compostos no interior dos microorganismos, principalmente a guanina e a adenina presente no DNA. Por esta razão, o ETO é extremamente eficiente na eliminação da maioria dos microorganismos, seja na forma vegetativa ou de esporos. Existem, porém, limitações quanto ao uso do ETO: inicialmente o vapor de ETO é explosivo quanto atinge a concentração de $3 \%$ no ar, além disso, o composto é tóxico, potencialmente cancerígeno, teratogênico, mutagênico e neurotóxico. Tendo em vista tais limitações, a utilização de materiais esterilizados por ETO requer uma série de passos de segurança. Já embutido no processo de esterilização, há uma etapa de aeração que visa retirar o vapor e seus possiveis subprodutos presentes no equipamento. Tal etapa pode consistir apenas na circulação de ar estéril ou na combinação de ciclos de vácuo. A duração da aeração pode variar de algumas horas a um dia, dependendo das características dos materiais esterilizados. Além dessa etapa é imprescindivel que o vapor já utilizado de ETO seja tratado antes de ser eliminado para o ambiente. O tratamento muitas vezes consiste na reação do vapor com água para formação de etileno glicol. O uso de EPI (Equipamento de Proteção Individual) por todos os envolvidos no processo de esterilização é obrigatório para evitar ao máximo a exposição ao ETO. Durante o processo de esterilização, podem ser formados subprodutos na presença de íons cloro (etileno cloridrina) ou de água (etileno glicol), tais compostos também são tóxicos e de difícil remoção. Tendo em vista o contato direto que certos produtos médicos e tecidos transplantados tem com a corrente sangüínea e os órgãos dos pacientes, ambos não devem ser esterilizados com ETO, já que os resíduos deixados por tal processo, mesmo com os cuidados para redução e diminuição destes, apresentam riscos ao paciente devido a seus possiveis efeitos tóxicos(POSSARI, 2003a).

- Vapor de formaldeído: O emprego do vapor de formaldeído surgiu como uma das alternativas ao uso do ETO. A ação sobre microorganismos deste composto é conhecida dede 1888 e os primeiros estudos sobre a eficácia na forma de vapor datam de 1906. Porém apenas 
em 1966 foi desenvolvida uma técnica que permitisse o uso do vapor de formaldeído em baixas temperaturas. A técnica, conhecida por LTSF (do inglês Low Temperature Steam and Folmaldehyde Sterilization) permite o uso do vapor de formaldeído a $2 \%$ entre $56-60^{\circ} \mathrm{C}$. A atuação sobre microorganismos é semelhante a do ETO, alquilando proteinas e ácidos nucléicos no interior dos microorganismos. De maneira geral, o LTSF é superior ao ETO, sendo mais econômico, de mais fácil utilização e mais saudável para o meio ambiente e para a equipe que o utiliza. A principal limitação, contudo se encontra no fato que materiais que absorvam o formaldeído em grandes quantidades não poderem ser esterilizados por esta técnica já que há uma enorme dificuldade em eliminar o produto impregnado (POSSARI, 2003b).

- Plasma de peróxido de hidrogênio: Como descrito pelo próprio nome, esta técnica se baseia na associação de vapor de peróxido de hidrogênio com plasma de baixa temperatura. Tal tecnologia data dos anos 80 tendo sido aprovada pelo FDA (Food and Drug Administration) apenas em 1993. O mecanismo de ação de esterilização por plasma de peróxido de hidrogênio se dá pela formação de radicais livres, os quais reagem inespecificamente com inúmeros compostos celulares e levam a uma inativação eficiente de esporos, bactérias e vírus. Em comparação com o ETO, este método não é tóxico já que os subprodutos principais são água e oxigênio. Porém, há a necessidade de se investir em embalagens especiais para os produtos, estes não podem conter compostos que absorvam o peróxido, tais como celulose e derivados e a penetração não é ideal (POSSARI, 2005).

- Radiação UV: A radiação UV (ultra-violeta) é a parte do espectro eletromagnético que se encontra entre $15 \mathrm{~nm}$ e $400 \mathrm{~nm}$, porém a região de interesse nos processos de esterilização vai de 220 até $300 \mathrm{~nm}$ (SHECHMEISTER, 1991). Tal radiação tem sido amplamente utilizada como agente para esterilização de água, sendo eficiente contra bactérias e (oo)cistos (ANDERSON et al, 2003). O mecanismo de ação da radiação UV envolve, principalmente, a formação de dímeros de timina no DNA, os quais tem efeito letal sobre o microrganismo. 


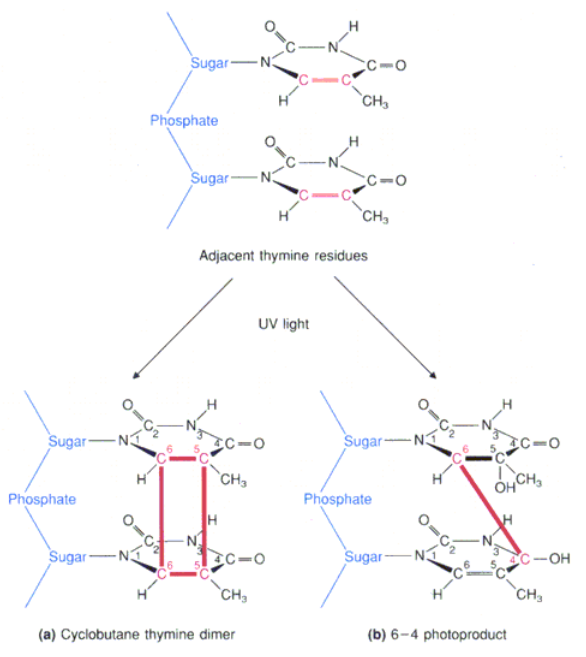

Figura 03: Formação de dimeros de timina pela radiação UV (STILLMAN, 2000).

Outros eventos também estão associados com a irradiação UV, porém seus efeitos sobre o microrganismo ainda não são claros. Tal radiação tem uma aplicação maior na esterilização de ar, água ou superficies, dada sua baixa penetrabilidade. Uma limitação do uso é que pode ocorrer uma recuperação do microrganismo quando este é exposto à luz visível ou próxima ao visivel, pois ocorre uma fotoreativação dos produtos danificados, levando a recuperação dos microrganismos (SHECHMEISTER, 1991).

- Radiação ionizante: O uso da radiação ionizante permite a esterilização de materiais em baixas temperaturas, inclusive do material congelado (DZIEDZIC-GOCLAWSKA, 2000). A radiação tem dois mecanismos de ação: um efeito direto sobre as moléculas dos microrganismos, quebrando, lesando ou fundindo as estruturas, principalmente do DNA, e outro efeito indireto causado pela formação de radicais livres com a radiolise da água. Tais radicais interagem com moléculas biologicamente importantes, em uma reação em cadeia, causando inúmeros danos ao microrganismo e culminando com a morte deste (YUSOF, 2001b). As principais vantagens do uso da radiação ionizante estão na sua boa penetrabilidade na matéria (especialmente em 
se tratando de raios $\gamma$ ), que permite um acesso maior ao locais contaminados além de minimizar a manipulação do material, já que não há necessidade de abertura ou troca das embalagens, na sua eficácia em eliminar microrganismos e no fato de não gerar quaisquer resíduos. Contudo o uso da radiação ainda é restrito devido à natureza das instalações necessárias para tal uso e pelo pouco conhecimento do que altas doses de radiação podem gerar de alterações na maioria dos materiais biológicos (DZIEDZIC-GOCLAWSKA, 2000).

O principal parâmetro para a avaliação da eficácia de um processo em reduzir uma dada carga microbiológica é estabelecido pelo valor $\mathrm{D}_{10}$, que é o valor necessário de exposição para reduzir a população total de microrganismos em $90 \%$ ou um log. O valor $\mathrm{D}_{10}$ é obtido se avaliando uma curva semilogaritmica de dose-reposta onde são cruzados os dados de dose pela diminuição da população. A unidade deste valor varia de acordo com o processo empregado, já que o fator envolvido no sucesso pode variar, e de acordo com o microrganismo, tendo em vista que a resistência a um dado processo varia de acordo com a espécie (PFLUG \& HOLCOMB, 1991). No caso da radiação ionizante o valor $\mathrm{D}_{10}$ é expresso em dose absorvida, cuja unidade é o Gray (Gy) (DZIEDZIC-GOCLAWSKA, 2000) e em média é de 2.5 kGy levando-se em conta os esporos mais resistentes a radiação (ARCAL, 2002).

\subsection{Radiação Ionizante}

A eficácia da radiação ionizante na inativação de microorganismos é conhecida desde 1886, quando foram realizados, por Roentgen, experimentos com raios-X. A primeira observação da ação de partículas beta e de raios gama, produzidos por isótopos naturais em diferentes materiais e em tecidos, foi feita por Pierre e Marie Currie (1899). Em 1929 (apud HERSON \& MATHOR, 2006) Marie Curie publicou um trabalho teórico sobre a inativação de bactérias por radiação.

Radiação ionizante é toda aquela capaz de gerar íons pelo deslocamento de elétrons de moléculas e átomos (DAHLAN, 2001). Existem dois grupos: 
- partículas de alta energia, tais como partículas a (alfa) e $\beta$ (beta), pósitrons e nêutrons, sendo estas obtidas pela desintegração radioativa de isótopos ou, no caso específico de partículaß e pósitrons, gerados por equipamentos específicos. De todas estas, os nêutrons possuem a capacidade extra de induzir radioatividade (SILVERMAN, 1991).

- ondas eletromagnéticas com pequeno comprimento de onda e grande energia, como radiação $\gamma$ (gama), obtida de radioisótopos, e raios X, gerados por maquinário (DAHLAN, 2001).

A quantidade de radiação absorvida pela matéria pode ser mensurada e a unidade no Sistema Internacional utilizada para esta grandeza é o Gray (Gy), que corresponde a 1 joule/quilograma (INMETRO, 2003). A medida de dose é importante, pois muitos efeitos desencadeados pela radiação, nocivos ou não, têm característica dose-dependente (DZIEDZIC-GOCLAWSKA, 2000).

Os íons e elétrons formados pela radiação ionizante são capazes de gerar radicais livres altamente reativos, os quais podem desencadear reações químicas com outros compostos que eventualmente estejam presentes ou mesmo entre si (DAHLAN, 2001; SILVERMAN, 2001). Tais interações podem levar a alterações nas propriedades físicas e químicas dos materiais (p. ex. JARRY et al., 2002; OLIVEIRA et al., 2005). Contudo estas alterações podem ser desejáveis, como visto em OTAGURO et al. (2004), e CHMIELESWSKI (2005).

A ionização gera um fenômeno em meio aquoso ou rico em água: a água passa por um processo de radiólise com formação de inúmeras espécies reativas. Tal radiólise está esquematizada a seguir: 


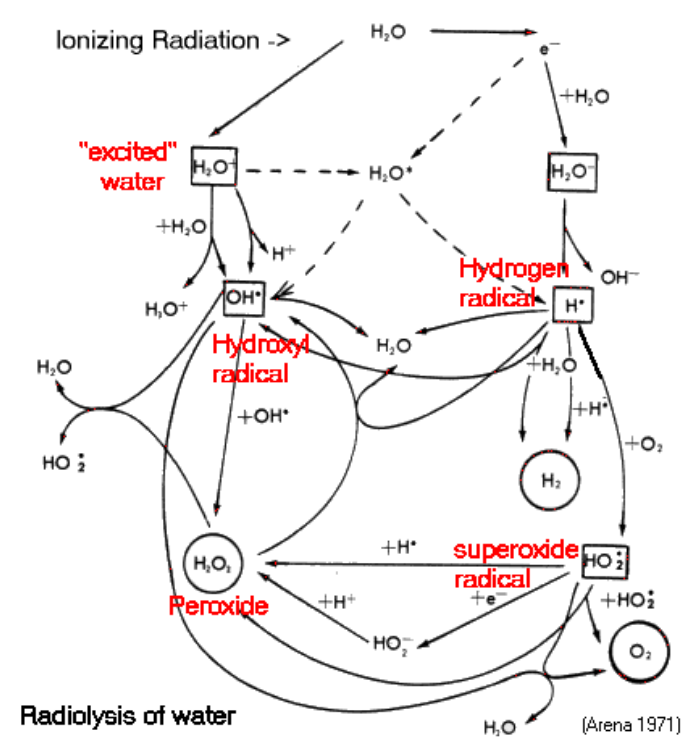

Figura 04: Radiólise da água. Os radicais livres formados se encontram em vermelho na figura. Esquema proposto por Arena (apud SCARR, 2005).

Esta situação é importante quando se analisa a interação da radiação ionizante com organismos vivos, os quais são compostos em grande parte por água. Nestes casos, inúmeros efeitos danosos podem vir a ocorrer da interação dos radicais livres com moléculas biologicamente importantes, tais como DNA e lipídeos de membrana (YUSOF, 2001b).

\subsection{Biomecânica}

Existem diversas definições para biomecânica, porém não há um enunciado geral sobre quais sejam exatamente seus objetos de estudo. Em parte, a biomecânica pode ser definida como "...o estudo da mecânica das coisas vivas...” (LAPEDES, D. apud BATISTA, 2001). Este conceito em si é, apesar de tecnicamente correto, pobre e não vislumbra todos as possiveis aplicações desta ciência. Uma definição corrente é que a biomecânica é "... a ciência de movimento que descreve o movimento do corpo humano utilizando os métodos da mecânica..." (BARROW \& BROWN apud BATISTA, 2001). Tal definição é uma das visões aplicáveis sobre a biomecânica e é comumente empregada na medicina, fisioterapia e educação física. Ela leva em conta conceitos práticos e de aplicação direta 
nas áreas envolvidas. Para o presente estudo, contudo, foi levada em conta a seguinte definição: "Biomecânica é o estudo e a análise da mecânica dos organismos vivos. O estudo e a análise pode ser feita em diversos niveis, do molecular, na qual biomateriais moleculares tais como colágeno e elastina, são considerados, ao macroscópico, seguindo toda gama até o nível dos tecidos e órgãos" (WIKIPEDIA, 2006b). Sob esta luz é possivel enquadrar dentro do objeto de estudo da biomecânica as propriedades dos biomateriais que compõe o corpo, tais como os ossos.

Estes, considerando sua composição, são definidos como compósitos, que são materiais formados por duas ou mais fases distintas. No caso específico, são três fases: aquosa, orgânica e mineral. A fase aquosa é essencialmente a água presente no líquido intersticial e sua função exata não é clara (YAMASHITA et al. 2001). A fase orgânica é composta principalmente por colágeno tipo I, que é composto por uma tripla hélice de cadeias polipeptídicas organizadas na forma de fibrilas. Estas fibrilas estão precisamente organizadas sobrepostas e em sentidos opostos entre camadas, mantendo o espaço constante entre as fibrilas adjacentes. Muitas ligações cruzadas entre as moléculas são formadas formando uma estrutura estável e porosa (DOWNEY \& SIEGEL. 2006). Tal estrutura é responsável pela elasticidade dos ossos (YAMASHITA et al, 2001). A fase mineral é composta por hidroxiapatita e fornece ao osso rigidez necessária para suas funções (DOWNEY \& SIEGEL, 2006).

As características mecânicas de um material podem ser mensuradas, para tanto, existem alguns conceitos de referência a serem considerados. No caso de ossos, duas definições são importantes: a de tensão (stress) e deformação (strain). A tensão em ensaios mecânicos é definida como força sobre unidade de área e pode ser classificada como: compressiva, que quando aplicada diminuí o tamanho do material; tensora, se aumentar o tamanho do material; ou de cisalhamento, quando promove o deslizamento de uma região do material em relação à outra. A sua unidade é o Pascal $(\mathrm{Pa})$, este em unidades mais elementares é definido como a força em Newtons (N) aplicada sobre uma área em metros quadrados $\left(\mathrm{m}^{2}\right)$. Em um sistema biológico, normalmente as três forças de 
tensão estão sendo aplicadas simultaneamente. A deformação é definida como a porcentagem de alteração no comprimento de um material, ou seja, quanto do comprimento original foi alterado.

A relação dessas duas constantes pode ser observada na curva de resposta típica de um ensaio universal de tensão-deformação como visto abaixo (Fig. 05):



Figura 05: Exemplo de curva de tensão deformação (baseado em DOWNEY \& SIEGEL, 2006)

Muitas informações podem ser retiradas da curva de tensãodeformação. De imediato, tal curva pode ser dividida em duas regiões, a de deformação elástica e a de deformação plástica (DOWNEY \& SIEGEL, 2006).

A região de deformação elástica corresponde à área sobre a curva onde há linearidade de resposta. Em tal região o material se comporta como uma mola, se deformando linearmente de acordo com a força aplicada e retornando a sua forma original ao se retirar a tensão. A inclinação da curva na região elástica é chamada de módulo elástico ou módulo de Young. Tal módulo é a medida da rigidez intrínseca do material. A rigidez pode variar de acordo com o individuo, por exemplo, há uma diferença entre a rigidez óssea de um atleta e de uma pessoa 
sedentária, contudo o módulo de elasticidade é próximo tendo em vista que este é característico para cada material (TURNER \& BURR, 1993).

Em alguns casos, há uma diferença de comportamento elástico do material dependendo da direção em que a força é aplicada neste. Tais materiais são conhecidos como anisotrópicos e tal característica é comum em compósitos de origem biológica, tais como madeira e ossos. Materiais cujas propriedades não variam com a direção são conhecidos como isotrópicos. (TURNER \& BURR, 1993). No caso de ossos, a direção preferencial varia se o osso é cortical ou trabecular. Considerando-se ossos corticais, a direção preferencial de resistência é a longitudinal, enquanto para o osso trabecular a direção preferencial é paralela ao sistema trabecular. O comportamento em ambos os casos condiz com a função de sustentação exercida pelo esqueleto já que corresponde a direção da força que é exercida quando o indivíduo está ereto (DOWNEY \& SIEGEL, 2006).

Há um ponto de transição no qual o material passa de uma deformação elástica para uma deformação plástica, que é permanente, independente da presença contínua de força aplicada e está relacionada com a deformação, quebra ou alteração na microestrutura do material. Este ponto é chamado de ponto de limite de escoamento na curva tensãodeformação. Tal ponto corresponde à tensão aplicada que leva a deformação plástica. A aplicação de tensão após este ponto pode levar a quebra ou ruptura do material ao se atingir o ponto de ruptura (TURNER \& BURR, 1993). Uma aplicação desse conceito pode ser utilizada em ossos. Quando se aplica uma tensão que corresponda a tal ponto, tem-se a ocorrência de uma fratura (DOWNEY \& SIEGL, 2006).

\subsubsection{DMA (Dynamical Mechanical Analysis)}

O DMA permite a determinação quantitativa das propriedades mecânicas de uma amostra ao submetê-la a uma carga oscilante, em uma dada freqüência, temperatura e durante um tempo determinado. A aplicação da carga tem por objetivo gerar uma deformação prédeterminada na amostra e a relação entre a força exercida para atingir tal 
deformação e as dimensões da amostra permitem obter a quantificação das características biomecânicas.

Os resultados obtidos com o DMA se encontram na porção inicial da curva de tensão-deformação já que as deformações causadas são normalmente muito pequenas em relação às dimensões do material. Esta técnica é assim interessante, pois não é destrutiva e permite que as amostras sejam re-analisadas ou utilizadas em outras técnicas.

A análise dinâmica representa uma situação mais semelhante àquela observada em seres vivos, já que nesses casos as tensões aplicadas são decorrentes do movimento e, assim, variáveis. Além disso, a maioria das fraturas ocorre em condições de aplicação dinâmica de forças (YAMASHITA et al, 2001).

O gráfico abaixo mostra um exemplo de curva obtida pelo método de DMA:



Figura 06: Exemplo de curva obtida com a DMA (baseado em resultados obtidos).

Tal curva apresenta a variação do módulo de elasticidade em função do tempo de ensaio. A curva que aparece juntamente com aquela referente ao módulo representa a tangente delta. Tal tangente é a quantificação da energia dissipada pelo material durante o ensaio dinâmico. 


\section{MATERIAL E MÉTODOS}

\subsection{Materiais}

Foram utilizados fêmures bovinos adquiridos em frigoríficos para simulação do processamento dos ossos de acordo com os requerimentos específicos para o armazenamento a $-70^{\circ} \mathrm{C}$ e para posterior irradiação (ISO-GUIDE 11.137 revisão 2006).

A irradiação das amostras foi feita no Centro de Tecnologia das Radiações - IPEN em fonte de Co60 (Gamacell).

Todos os demais reagentes utilizados foram de qualidade PróAnalisis e a água foi de qualidade Milli-Q.

O resíduo de material biológico não patogênico foi inativado com hipoclorito de sódio, colocado em sacos brancos e depositado no lixo biológico localizado na parte externa do biotério do IPEN. Sendo que o material foi obtido em frigoríficos autorizados para venda ao consumidor, não existiu a possibilidade de contaminação patogênica, portanto não houve a necessidade do material ser autoclavado antes do descarte no lixo biológico.

\subsection{Comitê de Ética}

O presente trabalho foi aprovado pelo Comitê de Ética em Pesquisa do IPEN e se encontra registrado sob o número de identificação 081/CEP-IPEN/SP.

\subsection{Métodos}

\subsubsection{Processamento dos ossos}

Todos os ossos bovinos analisados durante esse estudo foram submetidos a um processo inicial de limpeza, visando assim diminuir sua contaminação inicial e retirar todas as partes moles associadas ao osso:

O processo de limpeza se iniciou com a raspagem das partes moles e a retirada da medula óssea utilizando-se um bisturi para tanto.

Após a raspagem inicial, os ossos foram imersos em água destilada, para a retirada de sangue que estivesse presente em seu 
interior e para facilitar as subseqüentes raspagens de resíduos. A imersão teve a duração de 30 minutos.

A raspagem e a imersão em água destilada foram repetidas três vezes cada, buscando uma maior eficiência na limpeza.

A etapa final consistiu em um banho em peróxido de hidrogênio 10 volumes durante duas horas. Tal banho serve como uma etapa de redução da carga microbiológica além de atuar como agente clarificante.

Após o banho em peróxido, os ossos foram embalados um a um de acordo com as normas de embalagem para produtos a serem irradiados (embalagens duplas, plásticas, apirogênicas, não permeáveis ao ar e a água, passíveis de irradiação, identificadas e datadas). A estocagem se deu em freezer a uma temperatura de $-70^{\circ} \mathrm{C}$ (ISO-GUIDE 11.607 revisão 2006).

\subsubsection{Irradiação}

Para as análises de alterações induzidas pela radiação, as amostras foram irradiadas em um irradiador de Cobalto-60 tipo Gammacell, com atividade no momento das análises de 4.909,4 Ci e taxa de dose de 4,06 kGy/h (dimensões internas de $20 \mathrm{~cm}$ de altura x 14,5 cm de diâmetro).

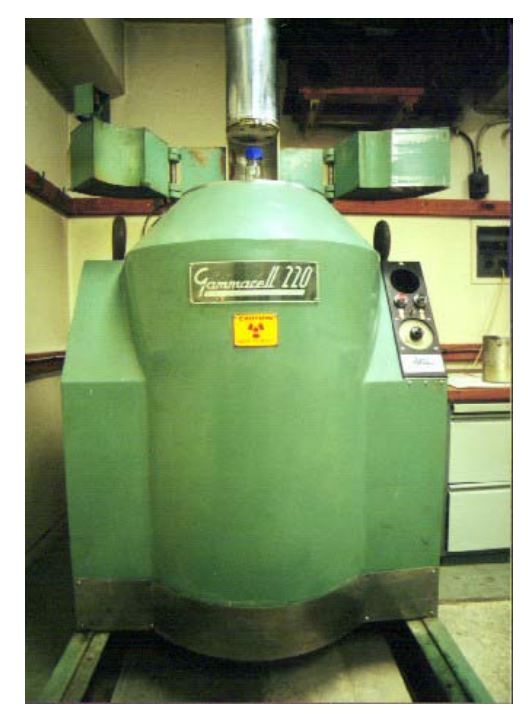

Figura 07: Gammacell

Como controles de dose foram utilizados dosimetros poliméricos Red Perspex (5-50 kGy). 
As doses avaliadas foram de 12,5; 25 e 50 kGy. Tais doses foram escolhidas devido a sua utilização na rotina (DZIEDZICGOCLAWSKA, 2000), em concordância com as normas vigentes (ISOGUIDE 11.607-1) e por se buscar linearidade para as posteriores análises. Como controle negativo foram utilizadas amostras não irradiadas, mas submetidas às mesmas condições de processamento, embalagem e estocagem. Todas as amostras foram irradiadas em gelo seco com o intuito de mantê-las o mais próximo das condições de estocagem e evitar quaisquer interferências decorrentes da variação de temperatura. Os dosimetros foram colocados na face interna e externa dos ossos, com intuito de se prever a dose obtida no interior dos ossos.

\subsubsection{Determinação da carga microbiológica}

Para esta análise foram utilizados anéis feitos a partir de cortes transversais de um fêmur bovino. Foram empregados quatro discos, cada um correspondendo a uma dose a ser analisada. Esses discos foram processados e irradiados como descrito anteriormente. Uma das amostras não foi irradiada, com o intuito de determinar a carga microbiológica inicial.

Após o processamento, em capela de fluxo laminar, as amostras foram imersas em $100 \mathrm{ml}$ de solução salina estéril dentro das embalagens originais e, em seguida, novamente lacradas. A seguir, todas as amostras foram agitadas em agitador orbital, à temperatura ambiente, em uma velocidade de $150 \mathrm{rpm}$ por 10 minutos. Tal procedimento visa retirar os microorganismos presentes na amostra, para posterior contagem.

Após a agitação, as amostras foram abertas novamente em capela de fluxo laminar e foram preparadas de acordo com o seguinte padrão: paras a amostra não irradiada foi feita diluição decimal em salina do extrato obtido, partindo de $10^{0}$ até $10^{-6}$. Paras a amostra irradiada com $12,5 \mathrm{kGy}$, foi feita diluição decimal de $10^{0}$ até $10^{-2}$. Já para as amostras de 25 kGy e 50 kGy, não foi feita diluição do extrato para contagem. Após as diluições, as amostras foram passadas individualmente por membranas filtrantes com poro de 0,45 $\mu \mathrm{m}$. 
As membranas filtrantes empregadas para as diluições foram divididas ao meio para se avaliar o crescimento de fungos, em Ágar Sabouraud, e bactérias, em TSA (Ágar Peptona Caseína - Tripticase Soy Ágar). As amostras foram encubadas em estufa $25^{\circ} \mathrm{C}$ (Sabouraud) e $32^{\circ} \mathrm{C}$ (TSA) e analisadas durante sete dias. A avaliação foi feita com a contagem das colônias (UFCs) ao final do tempo de encubação e o cálculo de UFCs total foi feito escolhendo as contagens nas placas onde se desenvolveram colônias em número próximo de 100, quando possível, tirando a média entre os números obtidos para fungos e bactérias e se multiplicando pela diluição.

\subsubsection{Cálculo teórico da dose}

De posse da carga microbiológica inicial foi calculada a dose teórica necessária para se atingir o valor de 10-6 UFCs determinado como segurança. Tal valor foi obtido segundo a seguinte fórmula:

$$
\mathrm{D}_{\mathrm{t}}=\mathrm{D}_{10} \times \log \left(10^{\text {contagem obtida }+6}\right)
$$

Onde Dt é a dose teórica para se atingir o SAL de $10^{-6}, \mathrm{D}_{10}$ é o valor de referência para contaminação por esporos, 10 contagem obtida é a potência de 10 encontrada durante a contagem de UFCs.

Os valores de empregados foram a contagem obtida na determinação da carga microbiológica (10 contagem obtida) e o valor de referência de 2,5 kGy para $\mathrm{D}_{10}$ (ARCAL, 2002).

\subsubsection{Análise mecanodinâmica}

\subsubsection{Suportes para cortes}

Para minimizar os erros decorrentes do uso de amostras heterogêneas para análise, foram desenvolvidos dois suportes para o corte dos ossos. Tais suportes foram desenhados avaliando os processos que seriam utilizados para obtenção das amostras, ou seja, cortes com serras circulares e discos.

Para os cortes feitos com serra, utilizou-se uma frezadora Romi F-20 com serra circular de $2 \mathrm{~mm}$ de espessura e $80 \mathrm{~mm}$ de raio. Tais 
cortes foram feitos em sentido longitudinal do osso e tiveram por objetivo facilitar a próxima fase de cortes.

Os cortes com disco foram feitos em um equipamento Isomet Low Speed Saw (Buehler) equipado com disco específico para corte de ossos (modelo Diamond Wafering Blade series 15HC Diamond $\mathrm{n}^{\circ} 11$ 4244). Com este conjunto obtiveram-se os cortes finais, os quais necessitavam maior precisão em seu paralalelismo e maior lisura.

As dimensões almejadas para as amostras foram 40-50mm $\mathrm{x}$ $0,5-1 \mathrm{~mm} \times 4 \mathrm{~mm}$ (comprimento $\mathrm{x}$ espessura $\mathrm{x}$ largura), as quais são adequadas para a análise biomecânica por DMA.

\subsubsection{DMA (Dynamical Mechanical Analysis)}

Para a análise de ossos, optou-se por utilizar a técnica de flexão em três pontos (three point bending), como exemplificado na figura abaixo:

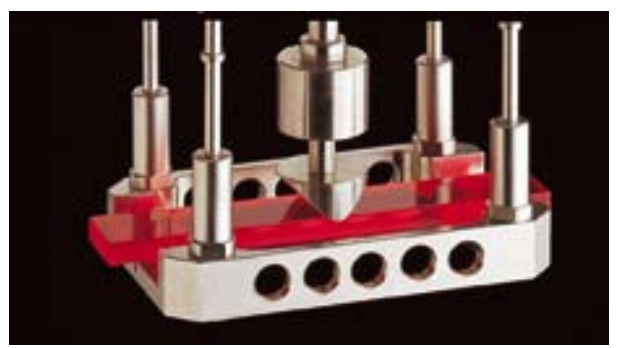

Figura 08: Técnica de flexão em três pontos (NETZSCH, 2006) O cálculo do módulo de Young (E) é obtido de acordo com a seguinte fórmula:

$$
\mathrm{E}=\frac{\mathrm{l}^{3}}{4 \mathrm{bh}^{3}} \cdot \frac{\mathrm{F}}{\mathrm{a}}
$$

Onde "E" é módulo de Young, "l" é distância entre os suportes, "b" é a largura da amostra, "h" é a espessura desta, "F" é a força aplicada e "a" é a amplitude de deformação.

Como condições de análise foi estabelecido que se aplicaria uma deformação de $60 \mu \mathrm{m}(\mathrm{a}=60 \mu \mathrm{m})$, a uma freqüência de $1 \mathrm{~Hz}$, a temperatura de $36 \pm 1{ }^{\circ} \mathrm{C}$. Todas as amostras foram analisadas com os suportes a uma distância de $40 \mathrm{~mm}(1=40)$.Todos as análises foram feitas em um intervalo de 10 minutos com leituras tomadas a cada minuto. 
Foram obtidos também os valores da tangente delta para as amostras analisadas.

\subsubsection{Ensaio de tensão $x$ deformação}

Os ensaios de tensão $\mathrm{x}$ deformação foram feitos em uma Máquina de Ensaios Universal (Instron). Durante este ensaio foram avaliadas a tensão de ruptura e a porcentagem de deformação das dimensões originais sofridas. As condições de ensaio foram um afastamento entre as garras de $10 \mathrm{~mm}$, deslocamento de $2 \mathrm{~mm} / \mathrm{min}$ e temperatura de $23{ }^{\circ} \mathrm{C}$ e umidade relativa de $50 \%$. A análise dos dados foi feita com o software fornecido pelo fabricante do equipamento.

Foram avaliadas as doses de 0 kGy, 12,5 kGy, 25 kGy e 50 kGy e as amostras utilizadas foram as mesmas dos ensaios de DMA sendo que estas foram lixadas para conferir um formato de halteres mais compativel com os ensaios de tensão x deformação.

\subsubsection{Análise estatística dos resultados}

A análise estatística foi feita com o programa Minitab (versão 14).

Foi analisada a distribuição normal dos valores obtidos para as amostras de 0 kGy com as leituras tanto do módulo de elasticidade quanto da tangente delta para avaliar o perfil no qual estas se encaixavam para análise.

Após esta analise optou-se pela utilização do teste nãoparamétrico de Kruskall-Wallis para análise de amostras procedentes de uma mesma população, seguindo os critérios estabelecidos por CAMPOS, 2000. Para a comparação das amostras, utilizou-se a média das dez medidas obtidas para cada ponto para análise. O erro considerado para validação da hipótese nula foi de $5 \%(p=0,05)$. 


\section{RESULTADOS}

\subsection{Processamento dos ossos}

Os ossos foram processados e embalados como descrito nos materiais e métodos, obtendo-se amostras para análise como observado na figura abaixo:

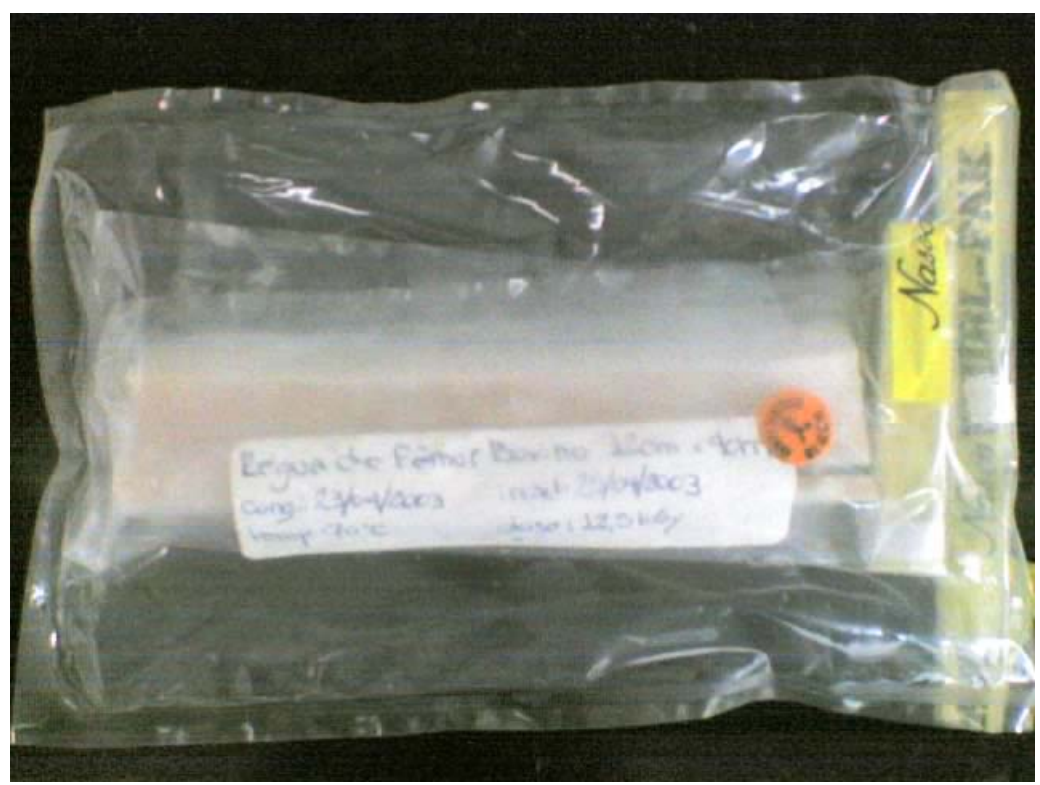

Figura 09: Ossos processados.

\subsection{Irradiação}

A dosimetria gerou o seguinte resultado:

Tabela 01. Dosimetria

\begin{tabular}{c|c|c}
\hline Dose solicitada (kGy) & Posição do dosimetro & Dose (kGy) \\
\hline \multirow{2}{*}{12,5} & Lateral externa & 13,2 \\
\cline { 2 - 3 } & Lateral interna & 12,5 \\
\hline \multirow{2}{*}{25} & Lateral externa & 26,1 \\
\cline { 2 - 3 } & Lateral interna & 25,5 \\
\hline \multirow{2}{*}{50} & Lateral externa & 50,6 \\
\cline { 2 - 3 } & Lateral interna & 50,1 \\
\hline
\end{tabular}




\subsection{Determinação da carga microbiológica}

O resultado das cargas microbiológicas encontradas nas amostras de ossos bovinos submetidas ao processamento e posterior irradiação se encontra abaixo na TAB.02:

Tabela 02. Carga microbiológica obtida

\begin{tabular}{|c|c|c|c|c|c|c|c|c|c|c|c|}
\hline \multicolumn{3}{|c|}{$\begin{array}{c}\text { Não irradiados } \\
\text { (OkGy) }\end{array}$} & \multicolumn{3}{|c|}{$12,5 \mathrm{kGy}$} & \multicolumn{3}{|c|}{ 25kGy } & \multicolumn{3}{|c|}{$50 \mathrm{kGy}$} \\
\hline \multirow{2}{*}{ Dil. } & \multicolumn{2}{|c|}{$\mathbf{N}^{\circ}$ UFC } & \multirow{2}{*}{ Dil. } & \multicolumn{2}{|c|}{$\mathbf{N}^{\circ} \mathbf{U F C}$} & \multirow{2}{*}{ Dil. } & \multicolumn{2}{|c|}{$\mathbf{N}^{\circ} \mathbf{U F C}$} & \multirow{2}{*}{ Dil. } & \multicolumn{2}{|c|}{$\mathbf{N}^{\circ} \mathbf{U F C}$} \\
\hline & TSA & Sab & & TSA & Sab & & TSA & Sab & & TSA & $\mathbf{S a b}$ \\
\hline $10^{0}$ & Inc. & Inc. & $10^{0}$ & 0 & 0 & $10^{0}$ & 0 & 0 & $10^{0}$ & 0 & 0 \\
\hline $10^{-1}$ & Inc. & Inc. & $10^{-1}$ & 0 & 0 & & & & & & \\
\hline $10^{-2}$ & Inc. & Inc. & $10^{-2}$ & 0 & 0 & & & & & & \\
\hline $10^{-3}$ & 297 & Inc. & & & & & & & & & \\
\hline $10^{-4}$ & 22 & 24 & & & & UF & Es to & ais & & & \\
\hline $10^{-5}$ & 5 & 1 & & & & & $6 \times 1$ & & & & \\
\hline $10^{-6}$ & 0 & 0 & & & & & & & & & \\
\hline
\end{tabular}

Legenda: Dil. = diluição

Inc. = incontáveis

\subsubsection{Cálculo teórico da dose}

Ao se substituir os valor na fórmula obteve-se uma dose de 27,5 kGy de dose para esterilização com um SAL 10-6 e uma dose de 12,5 kGy para esterilização sem limite de segurança.

\subsection{Análise mecanodinâmica}

5.4.1. Suportes para cortes

Após a análise das dimensões do equipamento, foram desenhados os seguintes projetos:

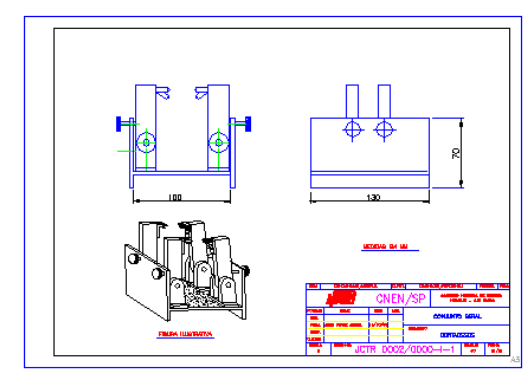

Figura 10: Projeto de suporte - Frezadora 


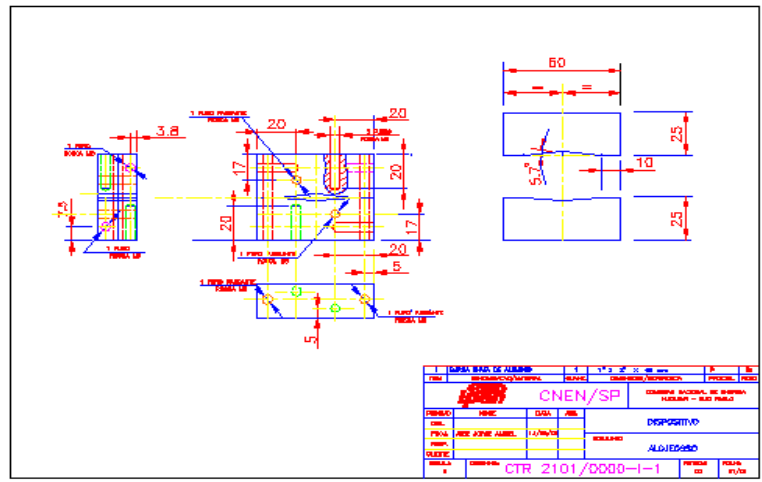

Figura 11: Projeto de suporte - Isomet

Os quais geraram os seguintes suportes:

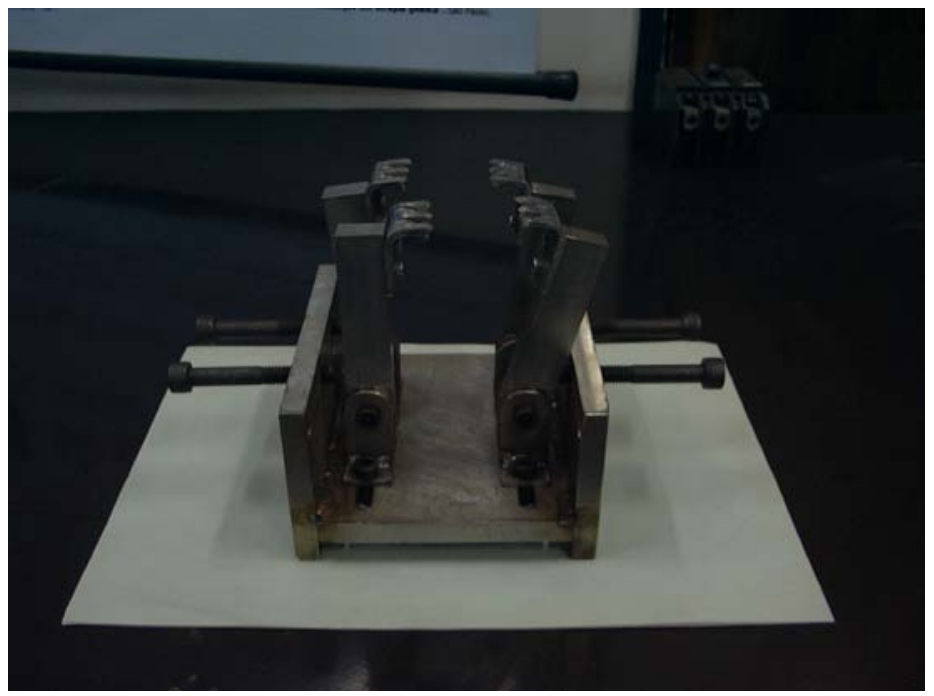

Figura 12: Suporte para frezadora

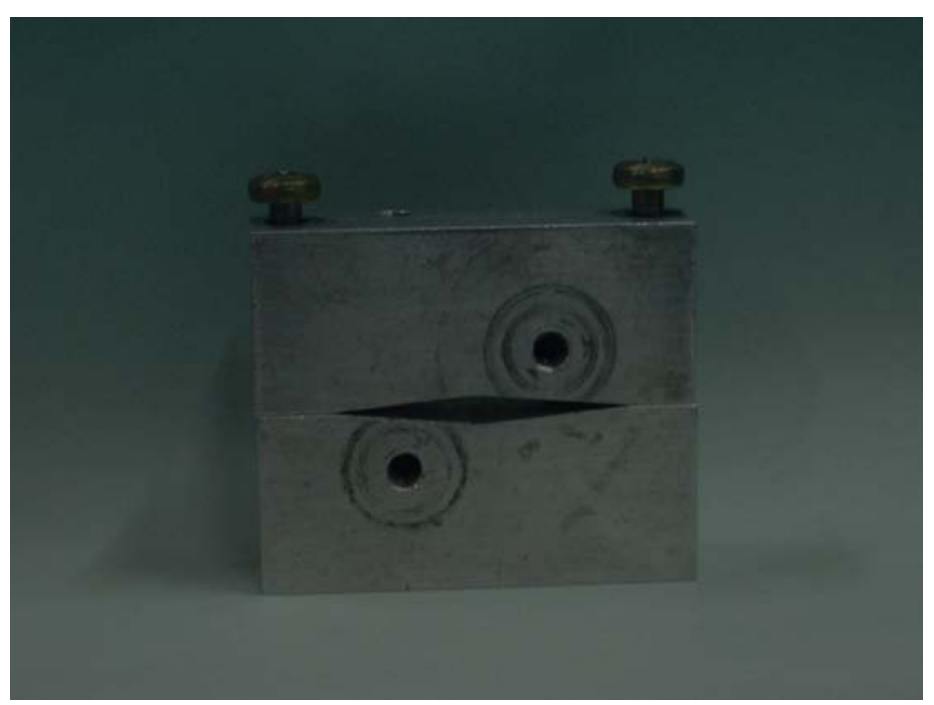

Figura 13: Suporte para Isomet 
As amostras obtidas podem ser observadas na figura abaixo:

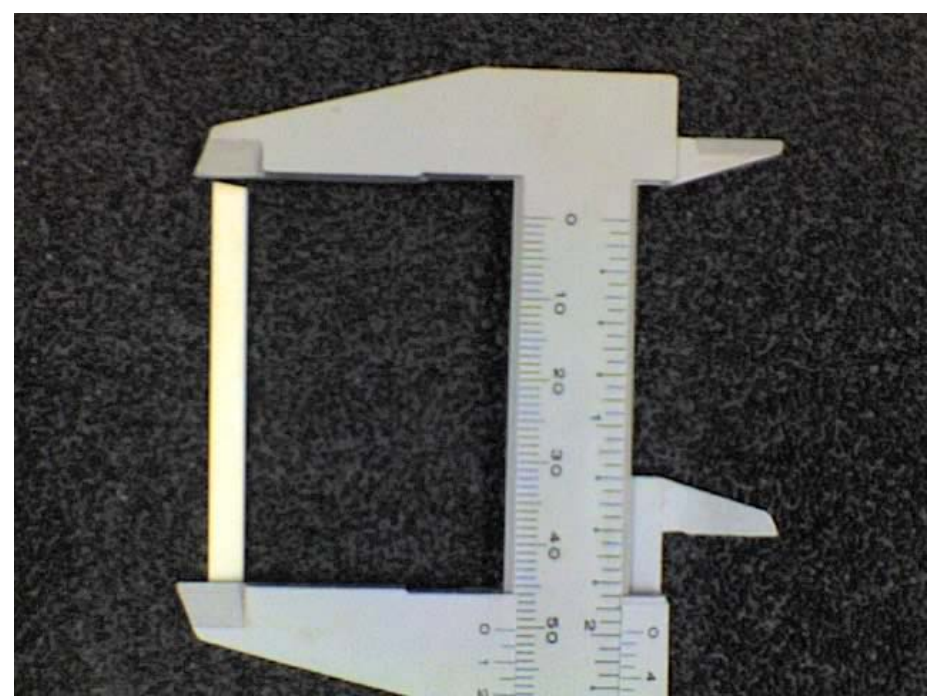

Figura 14: Amostras para análise biomecânica.

As dimensões das amostras obtidas variaram de acordo com a tabela abaixo:

Tabela 03. Dimensões das amostras para análise biomecânica

\begin{tabular}{l|l|c|c}
\hline \multirow{2}{*}{ Amostras } & \multicolumn{2}{|l|}{ Dimensões (mm) } & Desvio Padrão (mm) \\
\hline \multirow{2}{*}{ Réguas } & Largura & 4,1 & 0,2 \\
\cline { 2 - 4 } & Espessura & 0,7 & 0,2 \\
\hline
\end{tabular}

5.4.2. DMA (Dynamical Mechanical Analysis)

As médias dos resultados obtido com as leituras estão apresentados nas tabelas abaixo:

Tabela 04. Módulo de elasticidade

\begin{tabular}{c|c|c|c|c}
\hline $\begin{array}{c}\text { Dose } \\
(\mathbf{k G y})\end{array}$ & $\begin{array}{c}\text { Módulo de } \\
\text { elasticidade (GPa) }\end{array}$ & $\begin{array}{c}\text { Tangente } \\
\text { delta }\end{array}$ & $\begin{array}{c}\text { Número de } \\
\text { amostras }\end{array}$ & $\begin{array}{c}\text { Leituras por } \\
\text { amostra }\end{array}$ \\
\hline 0 & 28,34 & 0,10 & 8 & 10 \\
\hline 12,5 & 28,76 & 0,07 & 8 & 10 \\
\hline 25 & 31,44 & 0,05 & 7 & 10 \\
\hline 50 & 22,70 & 0,04 & 8 & 10 \\
\hline
\end{tabular}




\subsubsection{Tensão x Elongação}

As amostras para os ensaios de tensão x deformação apresentaram o seguinte aspecto:

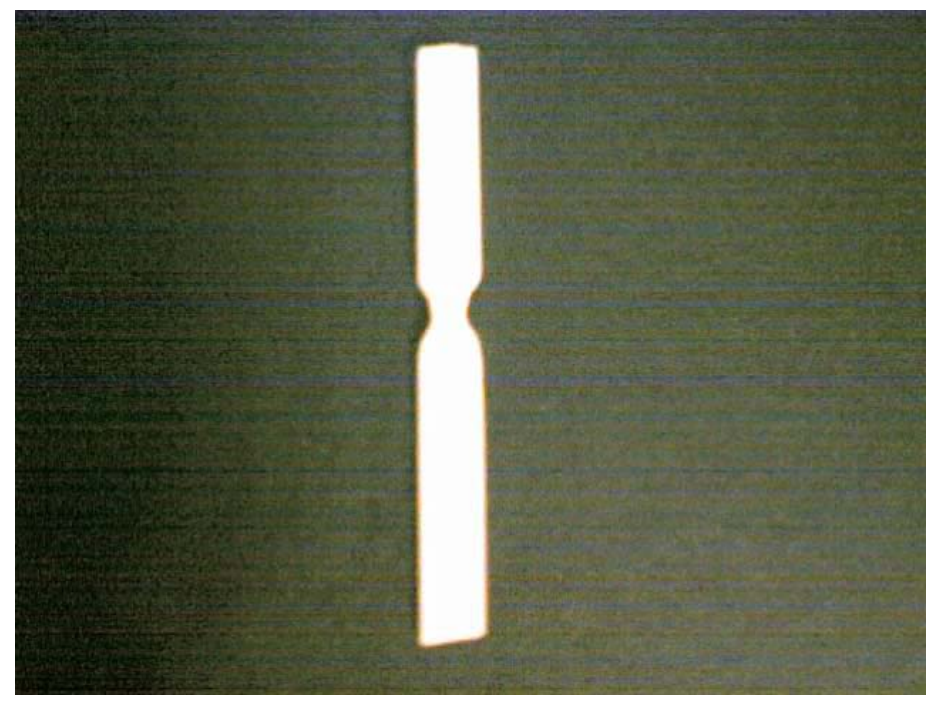

Figura 15: Amostra para ensaio de tensão x deformação.

abaixo:

Os ensaio de tensão x deformação geram os seguintes resultados

Tabela 05: Média dos resultados obtidos no ensaio de tensão x deformação

\begin{tabular}{l|c|c|c}
\hline Dose (kGy) & $\begin{array}{l}\text { Tensão de } \\
\text { Ruptura (MPa) } \\
\text { Média }\end{array}$ & $\begin{array}{l}\text { Deformação } \\
(\%)-\text { Média }\end{array}$ & $\begin{array}{l}\text { Número } \\
\text { de } \\
\text { amostras }\end{array}$ \\
\hline 0 & 70,66 & 24,16 & 4 \\
\hline 12,5 & 100,24 & 19,89 & 4 \\
\hline 25 & 60,48 & 17,37 & 4 \\
\hline 50 & 53,30 & 14,32 & 4 \\
\hline
\end{tabular}


5.4.4. Análise Estatística

A análise da distribuição normal gerou os seguintes gráficos:



Figura 16: Distribuição Normal das Amostras de 0 kGy para Módulo de Elasticidade.

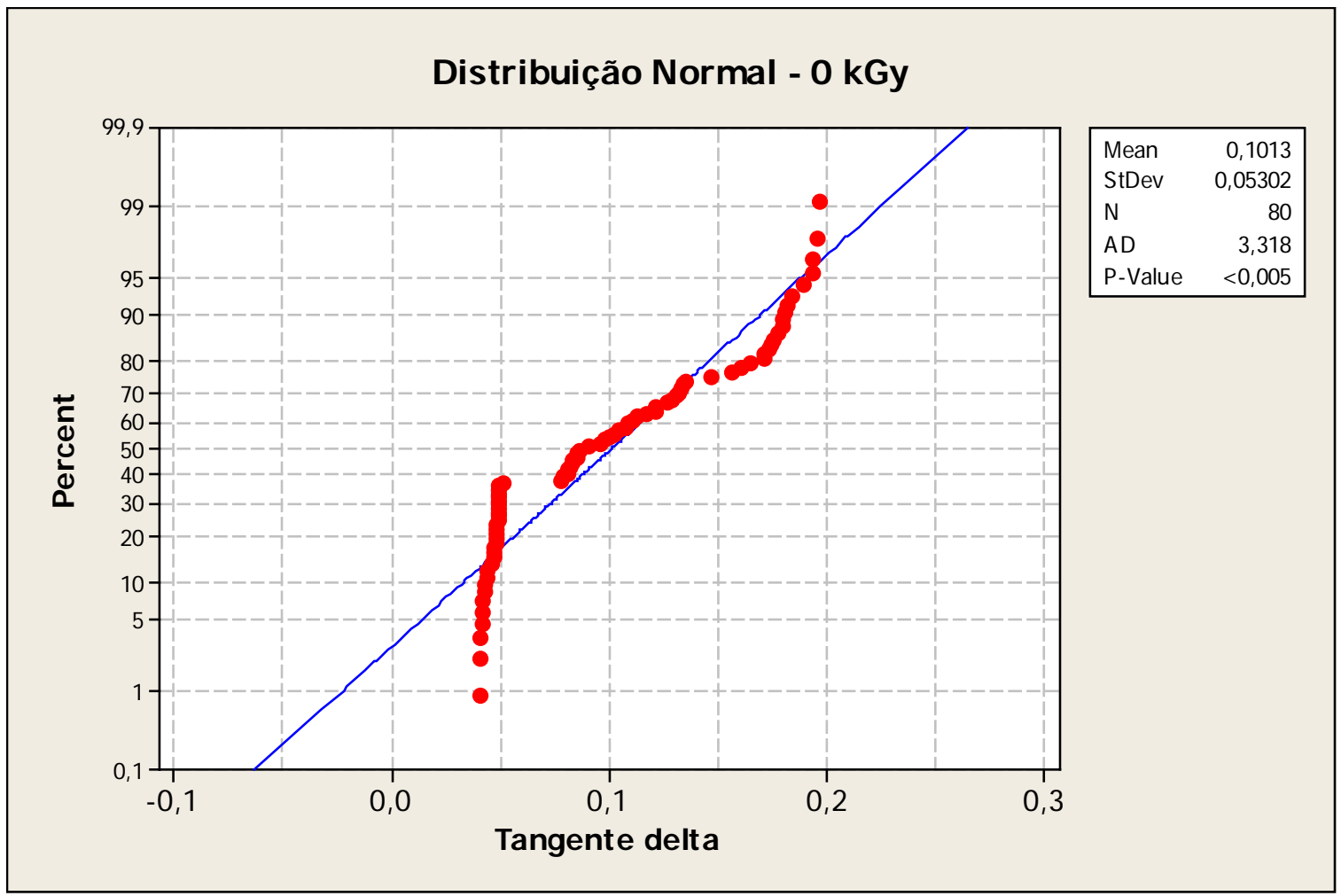

Figura 17: Distribuição Normal das Amostras de 0 kGy para tangente delta. 
A análise estatística gerou as seguintes tabelas:

Tabela 06: Análise de Kruskal-Wallis para Módulo de Elasticidade

\begin{tabular}{c|c|c|c}
\hline $\begin{array}{c}\text { Dose } \\
(\mathrm{kGy})\end{array}$ & $\mathbf{N}$ & Mediana & Rank médio \\
\hline 0 & 8 & 33,60 & 21,6 \\
\hline 12,5 & 8 & 21,87 & 11,0 \\
\hline 25 & 7 & 31,70 & 19,6 \\
\hline 50 & 8 & 25,82 & 12,3 \\
\hline
\end{tabular}

$\mathrm{p}=0,048$

Tabela 07: Análise de Kruskal-Wallis para Tangente Delta

\begin{tabular}{c|c|c|c}
\hline $\begin{array}{c}\text { Dose } \\
(\mathrm{kGy})\end{array}$ & $\mathbf{N}$ & Mediana & Rank médio \\
\hline 0 & 8 & 0,09 & 23,6 \\
\hline 12,5 & 8 & 0,05 & 19,1 \\
\hline 25 & 7 & 0,04 & 12,4 \\
\hline 50 & 8 & 0,04 & 8,4 \\
\hline
\end{tabular}

$\mathrm{p}=0,004$

Tabela 08: Análise de Kruskal-Wallis para Tensão de Ruptura

\begin{tabular}{c|c|c|c}
\hline $\begin{array}{c}\text { Dose } \\
(\mathbf{k G y})\end{array}$ & $\mathbf{N}$ & $\begin{array}{c}\text { Tensão de ruptura } \\
(\mathbf{M P a})-\mathbf{M e d i a n a}\end{array}$ & Rank Médio \\
\hline 0 & 4 & 76,80 & 10,0 \\
\hline 12,5 & 4 & 103,27 & 13,8 \\
\hline 25 & 4 & 54,48 & 5,8 \\
\hline 50 & 4 & 54,58 & 4,5 \\
\hline $\mathrm{p}=0,024$
\end{tabular}

Tabela 09: Análise de Kruskal-Wallis para Deformação

\begin{tabular}{c|c|c|c}
$\begin{array}{c}\text { Dose } \\
\text { (kGY) }\end{array}$ & $\mathbf{N}$ & $\begin{array}{c}\text { Deformação (\%) - } \\
\text { Mediana }\end{array}$ & Rank Médio \\
\hline 0 & 4 & 24,29 & 14,5 \\
\hline 12,5 & 4 & 20,21 & 9,4 \\
\hline 25 & 4 & 17,62 & 6,6 \\
\hline 50 & 4 & 14,27 & 3,5 \\
\hline $\mathrm{p}=0,009$
\end{tabular}




\section{DISCUSSÃO}

\subsection{Processamento dos ossos}

O processamento dos ossos armazenados em Bancos de tecidos biológicos é essencial para a preparação dos enxertos para seu uso (Fig. 09, p. 29). Além da retirada de partes moles não essenciais para o transplante, o processamento ajuda a diminuir a carga microbiológica inicial, devido à combinação de processo químico (banhos com peróxido de hidrogênio) e físico (raspagem). A padronização na embalagem serve como passo essencial de garantia de esterilidade durante a estocagem, para aumentar a vida útil do produto, já que atua como barreira fisica para evitar uma contaminação futura (OLIVEIRA et al., 2005). Todos os procedimentos de processamento e embalagem do material buscaram simular a rotina de Bancos de tecidos biológicos (HERSON et. al., 2002).

\subsection{Irradiação}

A principal preocupação quando se avalia um método de esterilização é se este será capaz de exercer sua atividade na amostra como um todo, garantindo assim que não haja focos onde possiveis contaminantes possam se proteger e desenvolver (RUSSEL, 1991). No modelo avaliado, pode-se comprovar que houve penetração homogênea da radiação em todo o osso, como visto pela pouca diferença entre as doses obtidas nas faces externa e interna (TAB. 01, p. 29).

A irradiação das amostras é o ponto chave de todo o processo. A garantia da eficácia desta, em relação à dose empregada, e a penetração homogênea permitem o uso seguro em pacientes, alem de assegurar a validade dos métodos empregados.

\subsection{Determinação da carga microbiológica}

No atual trabalho, não se visou avaliar a eficácia da radiação como agente de diminuição da carga microbiológica já que tais dados se encontram demonstrados na literatura (SILVERMAN, 1991; DZIEDZICGOCLAWSKA, 2005). Porém, é necessária uma avaliação da adequação das doses empregadas nesse estudo quanto a sua aplicação prática e a 
relevância dos dados obtidos. Primeiramente, foi necessário comprovar que partimos de amostras com contaminações iniciais compatíveis com a possibilidade de radioesterilização (vide Bancos de Tecidos, página 11), para que nossos resultados dos testes biomecânicos fossem confiáveis, mesmo nas amostras não irradiadas, tendo obtido médias de 4,6 x $10^{5}$ UFC. Por outro lado, foram efetuadas as determinações de carga microbiológica nas amostras irradiadas com diferentes doses para verificar a eficiência do procedimento de irradiação (PHILLIPS, 1997), confirmando um decréscimo na UFC já na primeira dose avaliada, confirmando o valor teórico de 12,5 kGy, suficiente para reduzir a população em 5 logs e obter zero UFC (TAB. 02, p. 30). Caso estes valores não coincidissem com os valores teóricos já seria um motivo para não continuidade do processo antes de uma revisão total do mesmo.

Desta forma, ao se considerar a carga microbiológica inicial de 4,6×105 UFCs, a dose de 12,5 kGy foi suficiente, levando-se em conta um valor teórico de 2,5 kGy para o valor de $\mathrm{D}_{10}$.

O valor teórico para esterilização de 27,5 kGy, obtido dentro dos limites de segurança preconizados (SAL 10-6), leva em conta apenas bactérias e fungos os quais são mais sensiveis a radiação do que vírus (PRUSS et. al., 2002). Dada a seleção inicial de doadores, requerida para doação (HERSON, 2002), muitas vezes não se faz necessário considerar tais contaminantes, contudo, a possibilidade de aumento de dose permitiria um descarte menor de doadores e assim disponibilizaria mais ossos para uso em transplante. Faz-se necessário, entretanto, uma avaliação específica de amostras contaminadas com vírus, para que se possa determinar a eficácia e segurança do processo de esterilização nestes casos.

\subsection{Análise biomecânica}

\subsubsection{Obtenção das amostras}

Ao se trabalhar com material de origem biológica, deve-se levar em consideração que existe uma variação nas características do material, tanto aqueles obtidos de um mesmo individuo quanto aqueles obtidos de 
um grupo de individuos semelhantes. Com este intuito, todo o trabalho de obtenção das amostras (vide Fig. 14, p. 32) pelo desenvolvimento de um sistema de suportes e cortes (vide Fig. 10 na p. 30 e Fig. 11 na p. 31), serve ao objetivo de diminuir as variáveis intrínsecas do tipo de material analisado. Desta forma, ao se conseguir amostras mais homogêneas, seria possivel diminuir o erro a ser levado em conta na análise dos resultados.

As dimensões obtidas para as amostras (vide TAB.03, p.32) apresentam uma variação pequena e bem próxima dos valores objetivados para análise, demonstrando a eficácia do sistema de cortes desenvolvido em fornecer amostras com pouca variação. $O$ comprimento não foi analisado tendo em vista que seu real valor em nada influencia os resultados. Os limites estabelecidos para este parâmetro se devem única e exclusivamente às dimensões mínimas de separação dos suportes (40 $\mathrm{mm}$ ) e o comprimento máximo da câmara de análise do equipamento utilizado.

\subsubsection{DMA}

Os valores encontrados para o módulo de elasticidade (TAB. 04, p. 32) foram semelhantes aqueles previamente descritos na literatura (REILLY et al, 1974). Estes autores, porém, se valeram de outro método para avaliar o módulo de elasticidade (tensão-elongação). A semelhança entre os valores serve como parâmetro de confirmação dos resultados obtidos.

\subsubsection{Ensaio de Tensão x Elongação}

Os dados obtidos com os testes de tensão $\mathrm{x}$ elongação permitiram avaliar a tensão máxima a qual as amostras puderam ser submetidas antes da quebra e o quanto estas se deformaram até que se atingisse a quebra. Os valores obtidos, em média, estão na TAB.05.

\subsubsection{Análise estatística}

A análise de distribuição normal dos valores de módulo de elasticidade e de tangente delta (Fig. 16 e Fig. 17, p. 33) evidencia que tais valores não apresentam uma distribuição normal típica tendo em vista que os pontos analisados se encontram muitos dispersos pelo gráfico. Tal 
perfil suscita o uso de testes não-paramétricos para a análise estatística dos dados, como feito neste trabalho. As TAB.05 e a TAB.06 (p.34) apresentam os resultados obtidos da análise comparativa entre os valores de módulo de elasticidade e tangente delta e os valores p apresentados $(p=0,048$ e $p=0,004)$ demonstram que há uma diferença estatisticamente significante entre os resultados obtidos. Tal dado, contudo, não descarta totalmente a utilização de altas doses de radiação para esterilização. Há a necessidade, porém, de se avaliar se tais alterações influenciam o enxerto in vivo e se estas não podem ser levadas em conta durante a recuperação do enxerto. Assim sendo no caso da prática de Bancos de Tecidos, deve-se informar o médico dessas alterações e cabe a este então definir se tais ossos se aplicam ou não em sua utilização prática.

Já no caso dos ensaios de tensão x deformação, pela análise estatística, foi evidenciada uma diferença entre as amostras para tensão de ruptura $(p=0,024)$ e entre a deformação sofrida por estas $(p=0,009)$. Ao se considerar a situação in vivo, tal condição não ocorre normalmente no caso de fraturas (YAMASHITA el at, 2001), contudo a diferença significativa na tensão de ruptura pode significar que in vivo há uma possibilidade de se atingir as condições necessárias para que ocorra uma fratura apenas com a tensão gerada pela movimentação usual do paciente (TURNER \& BURR, 1993).

\subsection{Considerações gerais}

O módulo obtido para ossos bovinos difere daquele descrito para ossos humanos (REILLY, 1974; YAMASHITA et al, 2001), contudo, como descrito na Introdução (p. 3), o presente estudo serve como base para estudos futuros a serem realizados com ossos humanos. 


\section{CONCLUSÕES}

O uso da radiação ionizante na esterilização de enxertos ósseos é uma opção viável e interessante, tanto do ponto de vista prático, dado sua facilidade de aplicação; do ponto de vista econômico, tendo em vista o baixo custo relativo envolvido no processo; quanto do ponto de vista social, pois permite uma esterilização sem resíduos tóxicos para o ambiente, para o paciente e para o corpo médico, além de abrir caminho para esterilização de material considerado impróprio para transplante.

O sistema para cortes desenvolvido neste trabalho permite a obtenção de amostras homogêneas. Tal sistema pode ser utilizado para inúmeras aplicações que envolvam cortes para preparação de material para análise precisa. De posse das amostras, a avaliação do módulo de elasticidade se tornou mais acessivel e com menor tendência à variação intra-amostras.

Com relação as alterações nas características mecânicas, estas necessitam de uma avaliação de seu impacto in vivo, para comprovação de até que ponto estas influenciam na recuperação do paciente e podem servir com critério para não utilização de doses maiores, as quais possibilitariam a inclusão de doadores anteriormente descartados na triagem por exemplo. 


\section{REFERÊNCIAS BIBLIOGRÁFICAS}

ANDERSON, W.B.; HUCK, P.M.; DIXON, D.G.; MAYFIELD, C.I. Endotoxin Inactivation in Water by Using Medium-Pressure UV Lamps. Applied and Environmental Microbiology, v.69, nº5, p. 3002-3004, 2003.

ARCAL (Acuerdo Regional de Cooperación para la Promoción de la Ciencia y Ttecnologia Nucleares en América Latina y el Caribe), Report of the expert meeting: Quality system for the production of irradiation sterilized tissue graft. Fev. 2002 (Project RLA/7/009 ARCAL LIX).

BATISTA, L.A. A biomecânica em educação física escolar. Perspectivas em Educação Física Escolar, v. 2, nº1, p. 36-49. 2001

BLOCK, S.S. (Ed). Disinfection, sterilization and preservation, $4^{\text {th }}$ Ed. Malvea, PA.: Lea \& Febiger, 1991, p. 29-58.

BONE CURRICULUM: base de dados. Disponivel em: < http://en.wikipedia.org/wiki/Bone>. Acessado em: 11/05/2006.

BOURROUL, S.A. Caracterização dos efeitos da radiação ionizante em pele humana para aloenxertos. 2004. Tese (Mestrado) - Instituto de Pesquisas Energéticas e Nucleares, São Paulo.

BRASIL, Lei $n^{\circ}$ 9434, de 04 de fevereiro de 1997. Dispõe sobre a remoção de órgãos, tecidos e partes do corpo humano para fins de transplante e tratamento e dá outras providências. D.O.U. - Diário Oficial da União; Poder Executivo, de 05 de fevereiro de 1997. Disponivel em: < http://elegis.anvisa.gov.br/leisref/public/showAct.php?id=3932\&word=>. Acessado em: 28/08/2006.

BRASIL, Decreto $\mathrm{n}^{\circ} 2268$, de 30 de junho de 1997. Regulamenta a Lei $\mathrm{n}^{\circ}$ 9.434, de 4 de fevereiro de 1997, que dispõe sobre a remoção de órgãos, tecidos e partes do corpo humano para fins de transplante e tratamento, e dá outras providências. D.O.U. - Diário Oficial da União; Poder Executivo, de 01 de julho de 1997. Disponivel em: < $\underline{\text { http://e- }}$ legis.anvisa.gov.br/leisref/public/showAct.php?id=6668word=>. Acessado em: $28 / 08 / 2006$.

BRASIL, Portaria $n^{\circ}$ 3407, de 05 de agosto de 1998. Aprova o Regulamento Técnico sobre as atividades de transplantes e dispõe sobre a Coordenação Nacional de Transplantes. D.O.U. - Diário Oficial da União; Poder Executivo, de 06 de agosto de 1998. Disponivel em: < $\underline{\text { http://e- }}$ legis.anvisa.gov.br/leisref/public/showAct.php?id=14502\&word=>. Acessado em: 28/05/2006. 
BRASIL, Portaria $n^{\circ}$ 263, de 31 de março de 1999. A utilização de tecidos, órgãos ou partes do corpo humano para fins cientificos somente será permitida depois de esgotadas as possibilidades de sua utilização em transplantes. D.O.U. - Diário Oficial da União; Poder Executivo, de 05 de abril de 1999. Disponivel em: < $\underline{\mathrm{http}: / / \mathrm{e}-}$ legis.anvisa.gov.br/leisref/public/showAct.php?id=1019\&word=>. Acessado em: $28 / 08 / 2006$.

BRASIL, Lei $\mathrm{n}^{\circ} 10211$, de 23 de março de 2001. Altera dispositivos da Lei $\mathrm{n}^{\circ}$ 9.434, de 4 de fevereiro de 1997, que "dispõe sobre a remoção de órgãos, tecidos e partes do corpo humano para fins de transplante e tratamento". D.O.U. - Diário Oficial da União; Poder Executivo, de 24 de março de 2001. Disponível em: < $\underline{\text { http://e- }}$ legis.anvisa.gov.br/leisref/public/showAct.php?id=4718word=>. Acessado em: $28 / 08 / 2006$.

BRASIL, Portaria $n^{\circ} 1686$, de 20 de setembro de 2002. Aprova, na forma do Anexo I desta Portaria, as Normas para Autorização de Funcionamento e Cadastramento de Bancos de Tecidos Musculoesqueléticos pelo Sistema Único de Saúde. D.O.U. - Diário Oficial da União; Poder Executivo, de 24 de setembro de 2002. Disponivel em: < $\underline{\text { http://e- }}$ legis.anvisa.gov.br/leisref/public/showAct.php?id=14815\&word=>. Acessado em: $28 / 08 / 2006$.

BUCKWALTER, J.A.; GLIMCHER, M.J.; COOPER, R.R.; BECKER, R. Bone biology, part I: structure, blood supply, cells, matrix, and mineralization. Instructional course lectures, v.45, p.386-371, 1996.

CAMPOS, G. M. Estatística para docentes e pós-graduandos. 2000: Livro publicado online pela Faculdade de Odontologia de Ribeirão Preto da Universade de São Paulo. Disponivel online em: < http://www.forp.usp.br/restauradora/gmc/gmc_livro/gmc_livro.html>. Acessado em: $12 / 12 / 2006$.

CHMIELEWSKI, A.C. Application of ionizing radiation in environmental protection. IAEA: Radiation Treatment of Gaseous and Liquid Effluents for Contaminant Removal, Dez 2005 (IAEA-TECDOC1473)

CROCI, A.T.; CAMARGO, O.P.; BITAR, G.; PEREIRA, S.L.B; MOREIRA, M.; FREITAS JR, S. de. Efeito do concentrado de plasma em falhas ósseas provocadas em fêmures de camundongos como estimulação de formação óssea. Estudo experimental. Acta Ortopédica Brasileira, v.11, $\mathrm{n}^{\circ} 4, \mathrm{p}$. 230-239. 2003

DAHLAN, K.Z.H.M. Radiation sciences. In: NATHER, A (Ed.) The Scientific Basis of Tissue Transplantation - Advances in Tissue Banking vol.5, $1^{\text {st }}$ Ed., Singapura: World Scientific Printers, 2001, p. 309341. 
DOWNEY, P.A. \& SIEGEL, M.I. Bone Biology and the Clinical Implications for Osteoporosis. Physical Therapy, v.86, n.1, p. 77-91. 2006.

DZIEDZIC-GOCLAWSKA, A The application of ionizing radiation to sterilize connective tissue allografts. In: PHILIPS, G.O. (Ed.) Radiation and Tissue Banking, $1^{\text {st }}$ Ed., Singapura: World Scientific Printers, 2000, p. 57-99.

DZIEDZIC-GOCLAWSKA, A.; KAMINSKI, A.; UHRYNOWSKATYSZKIEWCZ, I.; STACHOWICZ, W. Irradiation as a safety procedure in tissue banking. Cell and Tissue Banking, v. 6, p. 201-219. 2005.

GALEA, G, \& KERNEY, J.N. Clinical effectiveness of processed and unprocessed bone. Transfusion Medicine, v.15, p. 165-174. 2005

GOUVEIA, C.H.A. O efeito molecular e estrutural do hormônio tireoidiano no esqueleto. Arquivos Brasileiros de Endocrinologia e Metabologia, v.48, no 1 , p. 183-195. 2004.

HADDAD, F.S.; GARBUZ, D.S.; MASRI, B.A.; DUNCA, C.P.; HUTCHINSON, C.R.; GROSS, A.E. Femoral Bone Loss in Patients Managed With Revision Hip Replacement: Results of Circumferential Allograft Replacement. AAOS Institutional Course Lectures, v. 49, p.149-162. 2000.

HADDAD, F.S. \& DUNCAN, C.P. Cortical onlay struts in the treatment of periprosthetic femoral fractures. Instructional Course Lecture, v.52, p.291-300. 2003

HERNIGOU, P.; GRASS, G.; MARINETTO, G.; DORMONT, D. Inactivation of HIV by application of heat and radiation: Implication in bone banking with irradiated allograft bone. Acta Orthopaedica Scandinavica, n. 71, v. 5, p. 508-512. 2000

HERSON, M.R.; MATHOR, M.B.; FERREIRA, M.C. Bancos de Pele I: Aspectos Gerais e Administrativos, Planta Física e Controles de Qualidade. Revista Brasileira de Queimaduras, v.1, nº 1, p.35-40, 2001

HERSON, M.R.; MATHOR, M.B.; FERREIRA, M.C. Bancos de Pele II: Seleção de doadores - Captação, Processamento e Armazenamento dos Tecidos. Revista Brasileira de Queimaduras, v.2, nº 2, p. 15-21, 2002.

HERSON, M.R \& MATHOR, M.B. Bancos de Tecidos In: GARCIA, V.D.; ABUD, M.; NEUMANN, J.; PESTANA, J.O.M. Transplantes de Órgãos e Tecidos, $2^{a}$ Ed., São Paulo: Segmento Farma Editores Ltda. 2006, Cap. 16 , p. $157-168$.

INMETRO. Sistema Internacional de Unidades. $8^{\mathrm{a}} \mathrm{Ed}$, Rio de Janeiro; Inmetro. 2003. 
JARRY, C; LEROUX, J.C.; HAECK, J.; CHAPUT, C. Irradiating or Autoclaving Chitosan/Polyol Solutions: Effect on Thermogelling Chitosan$\beta$-glycerophosphate Systems. Chemical \& Pharmaceutical Bulletin, v.50, p. 1335-1340. 2002.

JOSLYN, L.J. Sterilization by heat. In: BLOCK, S.S. (Ed). Disinfection, sterilization and preservation, 4th Ed. Malvea, PA.: Lea \& Febiger, 1991, p. 495-526.

KLEIN, H.G. Pathogen inactivation technology: cleansing the blood supply. Journal of Internal Medicine, v. 257, p. 224-237. 2005.

KLEIN-NULEND, J.; BACABAC, R.G.; MULLENDER, M.G. Mechanobilogy of bone tissue. Pathologie Biologie, v. 53, p. 576-580. 2005.

KNESER, U.; SCHAEFER, D.J.; POLYKANDRIOTIS, E.; HORCH, R.E. Tissue Engineering of bone: the reconstructive surgeon's point of view. Journal of Cellular and Molecular Medicine, v.10, $\mathrm{n}^{\circ}$ 1, p.7-19. 2006.

LEVY, R.V. \& LEAHY, T.J. Sterilization Filtration. In: BLOCK, S.S. (Ed). Disinfection, sterilization and preservation, $4^{\text {th }}$ Ed. Malvea, PA.: Lea \& Febiger, 1991, p. 527-579.

MARKS, S.C. Jr; POPOFF, S.N. Bone cell biology: the regulation of development, structure, and function in the skeleton. American Journal of Anatomy, v.183, p. 1-44, 1988.

MONIG, H.J. \& VON VERSEN, R. Standards, Regulatory and Quality Systems, Whithin a Global Context. In: PHILIPS, G.O. (Ed.) Radiation and Tissue Banking, $1^{\text {st }}$ Ed., Singapura: World Scientific Printers, 2000, p. 01-55.

NATHER, A. Biology of healing of large deep-frozen cortical bone allografts. In: NATHER, A (Ed.) The Scientific Basis of Tissue Transplantation Advances in Tissue Banking vol.5, $1^{\text {st }}$ Ed., Singapura: World Scientific Printers, 2001, p. 434-454.

NETZSCH: Nezsch - Leading Thermal Analysis. - Productus/Solutions DMA 242 C. 2006. Página com informações técnicas sobre equipamentos para DMA. Disponivel em: < http://www.ngb.netzsch.com/en/products/detail/pid,20,t,2.html > . Ultima acesso em: 13/12/2006.

OLIVEIRA, A.L.; MANO, J.F.; SAN ROMÁN, J.; REIS, R.L. Study of the influence of $\beta$-radiation on the properties and mineralization of different starch-based biomaterials. Journal of Biomedical Materials Research Part B: Applied Biomaterials, v. 74B, nº 1, p.560 - 569. 2005 
OTAGURO, H.; ARTEL, B.W.H.; PARRA, D.F.; CARDOSO, E.C.L.; LIMA, L.F.C.P.; LUGÃO, A.B. Comportamento do polipropileno em presença de monômeros trifuncionais no estado fundido e sua influência na morfologia. Polímeros, v. 14, n², p.99-104. 2004

PHILIPS, G.O. Module 5: Processing. In: Multimedia distance learning package on tissue banking, $1^{\text {st }}$ Ed., Singapura: IAEA, 1997.

PFLUG, I.J. \& HOLCOMB, R.G. Principles of the thermal destruction of microorganisms. In: BLOCK, S.S. (Ed). Disinfection, sterilization and preservation, 4th Ed. Malvea, PA.: Lea \& Febiger, 1991, p. 85-128.

POSSARI, J.F. Esterilização por óxido de etileno. $1^{\text {a }}$ Ed. São Paulo, SP.: Iátria, 2003a.

POSSARI, J.F. Esterilização por plasma de peróxido de hidrogênio. $1^{\mathrm{a}}$ Ed. São Paulo, SP.: Iátria, 2005.

POSSARI, J.F. Esterilização por vapor de baixa temperatura e formaldeido. $1^{a}$ Ed. São Paulo, SP.: Iátria, 2003b.

PRUSS, A.; KAO; N.; GOHS, U.; KOSCIELNY, J.; VON VERSEN; R.; PAULI, G. Effect of gama irradiation on human cortical bone transplants contaminated with enveloped and non-enveloped virus. Biologicals, n. 30, p. 125-133. 2002

REILLY, D.T.; BURSTEIN, A.H.; FRANKEL, V.H. The elastic modulus for bone. Jounal of Biomechanics, n. 7, p. 271-275. 1974

ROSS, F.P. \& CHRISTIANO, A.M. Nothing but skin and bone. The Journal of Clinial Investigation, v.116, $\mathrm{n}^{\circ} 5$, p. 1140-1149. 2006.

RUSSEL, A.D. Principles of antimicrobial activity. In: BLOCK, S.S. (Ed). Disinfection, sterilization and preservation, $4^{\text {th }}$ Ed. Malvea, PA.: Lea $\&$ Febiger, 1991, p. 29-58.

RUTALA, W.A. \& WEBER, D.J. Disinfection and Sterilization in Health Care Facilities: What Clinicians Need to Know. Clinical Infectious Diseases, v. 39, p. 702-709. 2004.

SCARR, S.M. Radiolysis of Water, 2005. Apresenta conteúdo sobre radiolise da água. Disponivel em: < http://www.mun.ca/biology/scarr/Radiolysis_of_Water.html>. Acesso em: 25/05/2006.

SHECHMEISTER, I.L. Sterilization by ultraviolet irradiation. In: BLOCK, S.S. (Ed). Disinfection, sterilization and preservation, $4^{\text {th }}$ Ed. Malvea, PA.: Lea \& Febiger, 1991, p. 553-565. 
SILVERMAN, G.J. Sterilization and preservation by ionizing irradiation. In: BLOCK, S.S. (Ed). Disinfection, sterilization and preservation, $4^{\text {th }}$ Ed. Malvea, PA.: Lea \& Febiger, 1991, p. 566-579.

STILLMAN, J. Occidental College Molecular Biology Home Page. Mantido por Grace Fisher-Adams, 2000. Apresenta conteúdo sobre biologia molecular com figuras ilustrativas. Disponivel em: < http://departments.oxy.edu/biology/Stillman/bi221/mobio_main.html> . Acesso em: 24/05/2006.

TURNER, C.H. \& BURR, D.B. Basic Biomechanical Measurements of Bone: A Tutorial. Bone, v. 14, p. 595-608. 1993.

VASTEL, L.; MEUNIER, A.; SINEY, H.; SEDEL, L.; COURPIED, J.-P. Effects of different sterilization processing methods on the mechanical properties of human cancellous bones. Biomaterials, v. 25, p. 2105-2110, 2004.

WIKIPEDIA: banco de dados. Disponivel em: < http://en.wikipedia.org/wiki/Bone>. Acesso em: 11/05/2006.

WIKIPEDIA: banco de dados. Disponivel em: < http://en.wikipedia.org/wiki/Biomechanics>. Acesso em: 11/09/2006b.

YAMASHITA, J.; FURMAN, B.R.; RAWLS, H.R.; WANG, X.; AGRAWAL, C.M. The use of dynamic mechanical analysis to assess the viscoelastics properties of human cortical bone. Journal of Biomedical Material Research, v. 58, p. 47-53. 2001.

YUSOF, N. Bioburden Estimation in Relation to Sterilization. In: NATHER, A (Ed.) The Scientific Basis of Tissue Transplantation - Advances in Tissue Banking vol.5, $1^{\text {st }}$ Ed., Singapura: World Scientific Printers, 2001a, p. 200-211.

YUSOF, N. Effect of Radiation on Microorganisms - Mechanism of Radiation Sterilization In: NATHER, A (Ed.) The Scientific Basis of Tissue Transplantation - Advances in Tissue Banking vol.5, $1^{\text {st }}$ Ed., Singapura: World Scientific Printers, 2001b, p. 342-357. 